\title{
Deletion of Class II ADP-Ribosylation Factors in Mice Causes Tremor by the Nav1.6 Loss in Cerebellar Purkinje Cell Axon Initial Segments
}

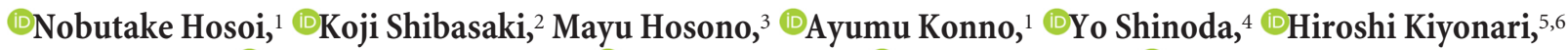 \\ Kenichi Inoue, ${ }^{6}$ @Shin-ichi Muramatsu, ${ }^{7}$-Yasuki Ishizaki, ${ }^{2}$ 'Hirokazu Hirai, ${ }^{1}$ Teiichi Furuichi, ${ }^{8}$ \\ and $\odot$ Tetsushi Sadakata ${ }^{3}$ \\ Departments of ${ }^{1}$ Neurophysiology and Neural Repair, ${ }^{2}$ Molecular and Cellular Neurobiology, ${ }^{3}$ Education and Research Support Center, Gunma University \\ Graduate School of Medicine, Maebashi, Gunma 371-8511, Japan, ${ }^{4}$ Department of Environmental Health, School of Pharmacy, Tokyo University of \\ Pharmacy and Life Sciences, Hachioji, Tokyo 192-0392, Japan, ${ }^{5}$ Genetic Engineering Team, ${ }^{6}$ Laboratory for Animal Resources, RIKEN Center for \\ Biosystems Dynamics Research, Kobe, Hyogo 650-0047, Japan, ${ }^{7}$ Department of Neurology, Jichi Medical University, Shimotsuke, Tochigi 329-0498, Japan, \\ and ${ }^{8}$ Department of Applied Biological Science, Tokyo University of Science, Noda, Chiba 278-8510, Japan
}

ADP-ribosylation factors (ARFs) are a family of small monomeric GTPases comprising six members categorized into three classes: class I (ARF1, 2, and 3), class II (ARF4 and 5), and class III (ARF6). In contrast to class I and III ARFs, which are the key regulators in vesicular membrane trafficking, the cellular function of class II ARFs remains unclear. In the present study, we generated class II ARF-deficient mice and found that $\mathrm{ARF} 4^{+/-} / \mathrm{ARF} 5^{-1-}$ mice exhibited essential tremor (ET)-like behaviors. In vivo electrophysiological recordings revealed that ARF4 ${ }^{+/-} / \mathrm{ARF}^{-/-}$mice of both sexes exhibited abnormal brain activity when moving, raising the possibility of abnormal cerebellar excitability. Slice patch-clamp experiments demonstrated the reduced excitability of the cerebellar Purkinje cells (PCs) in $\mathrm{ARF} 4^{+/-} / \mathrm{ARF}^{-1-}$ mice. Immunohistochemical and electrophysiological analyses revealed a severe and selective decrease of poreforming voltage-dependent $\mathrm{Na}^{+}$channel subunit Nav1.6, important for maintaining repetitive action potential firing, in the axon initial segment (AIS) of PCs. Importantly, this decrease in Nav1.6 protein localized in the AIS and the consequent tremors in ARF4 ${ }^{+/-}$/ ARF5 $^{-1-}$ mice could be alleviated by the PC-specific expression of ARF5 using adeno-associated virus vectors. Together, our data demonstrate that the decreased expression of the class II ARF proteins in ARF4 ${ }^{+/-} / A R F 5^{-/-}$mice, leading to a haploinsufficiency of ARF4 in the absence of ARF5, impairs the localization of Nav1.6 to the AIS and hence reduces the membrane excitability in PCs, resulting in the ET-like movement disorder. We suggest that class II ARFs function in localizing specific proteins, such as Nav1.6, to the AIS.

Key words: ARF; axon initial segment; essential tremor; sodium channel

Significance Statement

We found that decreasing the expression of class II ARF proteins, through the generation of ARF4 ${ }^{+/-} / \mathrm{ARF}^{-/-}$mice, impairs Nav1.6 distribution to the axon initial segment (AIS) of cerebellar Purkinje cells (PCs), thereby resulting in the impairment of action potential firing of PCs. The ARF4 ${ }^{+/-} / \mathrm{ARF}^{-1-}$ mutant mice exhibited movement-associated essential tremor (ET)-like behavior with pharmacological profiles similar to those in ET patients. The exogenous expression of ARF5 reduced the tremor phenotype and restored the localization of Nav1.6 immunoreactivity to the AIS in ARF4 ${ }^{+/-} / \mathrm{ARF}^{-1-}$ mice. Thus, our results suggest that class II ARFs are involved in the localization of Nav1.6 to the AISs in cerebellar PCs and that the reduction of class II ARF activity leads to ET-like movement disorder.

\section{Introduction}

Neurons require transmembrane cation $\left(\mathrm{Na}^{+}, \mathrm{Ca}^{2+}\right)$ influx for their depolarization and generation of the action potential (AP;

Received Aug. 5, 2018; revised May 14, 2019; accepted May 31, 2019.

Author contributions: T.S. designed research; N.H., K.S., M.H., A.K., Y.S., H.K., K.I., and T.S. performed research; N.H., K.S., and T.S. analyzed data; T.S. wrote the first draft of the paper; S.-i.M., Y.I., H.H., and T.F. edited the paper; N.H., K.S., and T.S. wrote the paper.
Nicholls et al., 2001). Various ion channels and receptors, such as voltage-gated $\mathrm{Na}^{+}$channels, voltage-gated $\mathrm{Ca}^{2+}$ channels, and glutamate receptors, contribute as an excitatory drive in neurons. 
Especially, the regulated clustering of voltage-gated $\mathrm{Na}^{+}$channels toward the axon initial segment (AIS) is responsible for the initiation of AP (Kole and Stuart, 2012). Several types of voltagegated $\mathrm{Na}^{+}$channels and modulatory proteins are localized to the AIS and perform unique neuronal activities and functions. Although neuronal $\mathrm{Na}^{+}$channels conserve a common ankyrinbinding motif, it is unclear which molecular mechanisms regulate the specific clustering of AIS $\mathrm{Na}^{+}$channels (Zhang and Rasband, 2016). Ion-channel targeting is strictly regulated during endoplasmic reticulum (ER)-Golgi transport, and modulated by ADP-ribosylation factor (ARF) proteins (Donaldson and Jackson, 2011). ARF proteins belong to the Ras superfamily of small GTPases and regulate protein trafficking through secretory and endocytic pathways (Donaldson and Jackson, 2011; MizunoYamasaki et al., 2012). Six ARF proteins (ARF1-6) have been identified so far. Among those, only five types of ARFs are expressed in humans because the ARF2 gene has been lost in the human genome (Cockcroft et al., 1994). On the basis of amino acid sequence homology, the six ARFs are grouped into the following three classes: class I (ARF1-3), class II (ARF4 and 5), and class III (ARF6). The class I ARFs localize at the ER and Golgi and play an important role in vesicular trafficking between these intracellular organelles (Donaldson and Jackson, 2011). ARF6 primarily localizes to the plasma membrane and endosomal compartments, and regulates membrane dynamics-based cellular events such as endocytosis, exocytosis, and endosomal recycling (Schweitzer et al., 2011). Although class II ARFs have been implicated in Golgi-to-ER retrograde transport and dense-core vesicle synthesis (Volpicelli-Daley et al., 2005; Sadakata et al., 2010), little is known about their role in vivo.

The aim of the current study was to clarify the role of class II ARFs on normal brain functioning. Both ARF4 and ARF5 are widely expressed in the mouse brain, and ARF4 knock-out (KO) mice are embryonic lethal (Jain et al., 2012). To elucidate the functional roles of class II ARFs in vivo, we first generated an ARF5 KO (-/-) mouse line and crossed it with an ARF4 heterozygous $(+/-)$ mouse line to produce the class II ARF hypomorphic mouse line with the ARF4 $4^{+/-} / \mathrm{ARF}^{-/-}$genotype. Using ARF4 ${ }^{+/-} / \mathrm{ARF}^{-/-}$mice, we found that class II ARFs play an important role in the localization of Nav1.6 to the AIS of cerebellar Purkinje cells (PCs) and that class II ARF deficiency causes a severe essential tremor (ET) phenotype.

\section{Materials and Methods}

Animals. All procedures for the care and treatment of animals were performed according to the Japanese Act on the Welfare and Management of Animals and the Guidelines for the Proper Conduct of Animal Experiments issued by the Science Council of Japan. All experimental protocols were reviewed and approved by the Gunma University Animal Care and Experimentation Committee and by the Institutional Animal Care and Use Committee of the RIKEN Kobe Branch. The brain of Scn8 $\mathrm{a}^{\mathrm{tg} / \mathrm{tg}}$ mouse deprived of Nav1.6 expression (Burgess et al., 1995) was kindly provided by Dr. Miriam H. Meisler (Department of Human Genetics, University of Michigan).

Generation of ARF4 and ARF5 KO mice and genotyping. ARF4 and ARF5 KO mice [accession No. CDB0884K (ARF4) and CDB0885K (ARF5); http://www2.clst.riken.jp/arg/mutant mice list.html] were gen-

JP15H05934, JP17K07103, and JP19K06900. We thank Dr. Miriam H. Meisler (Department of Human Genetics, University of Michigan) for providing us with the brain of $S \mathrm{cn} 8 \mathrm{a}^{\mathrm{tg} / \mathrm{tg}}$ mouse.

The authors declare no competing financial interests.

Correspondence should be addressed to Tetsushi Sadakata at sadakata-1024@umin.ac.jp or Nobutake Hosoi at nhosoi@gunma-u.ac.jp.

https://doi.org/10.1523/JNEUROSCI.2002-18.2019

Copyright $@ 2019$ the authors erated as described previously (http://www2.clst.riken.jp/arg/methods.html). The targeting vector contained two loxP sites and a neomycin resistance cassette for selection in embryonic stem (ES) cells derived from C57BL/6 mice (Kiyonari et al., 2010). For gene targeting, ES cell screening and chimera production were performed. The chimeric mice were mated with $\mathrm{C} 57 \mathrm{BL} / 6$ mice to generate $\mathrm{F} 1$ heterozygotes, which were then crossed with CAG-Cre mice (Sakai and Miyazaki, 1997), to produce ARF4 and ARF5 KO offspring. Genomic DNA was isolated from mouse ear punched tissues and yolk sac for genotyping. ARF4 KO mouse alleles were genotyped by allele-specific PCR with the following primers: ARF4 (forward primer) $5^{\prime}$-ctatgcagatggtgttaggc-3', ARF4 [wild-type (WT) primer] 5'-gccctccacatcaacacttc-3', and ARF4 (KO primer) 5'caatgctaggacaatgaggc- $3^{\prime}$. The ARF4 (forward) and ARF4 (WT) primer set yields a product of $140 \mathrm{bp}$, whereas the ARF4 (forward) and ARF4 (KO) primer set yields a product of $556 \mathrm{bp}$. ARF5 KO mouse alleles were genotyped using allele-specific PCR with the following primers: ARF5 (forward primer) $5^{\prime}$-acttgagaaatgggtcaccg-3', ARF5 (WT primer) $5^{\prime}$ cgatctctgcaaaggacaca- $3^{\prime}$, and ARF5 (KO primer) $5^{\prime}$-cgagggaaaagctg tgttgt-3'. The primer set ARF5 (forward) and ARF5 (WT) yields a product of $156 \mathrm{bp}$ and primer set ARF5 (forward), ARF5 (KO) yields a product of $280 \mathrm{bp}$. All of the engineered animals studied were backcrossed onto $\mathrm{C} 57 \mathrm{BL} / 6 \mathrm{~J}$ for $>5$ generations.

Electroencephalogram and electromyogram recording and analysis. Electroencephalogram (EEG) electrodes that were connected to a $5 \mathrm{~mm}^{2}$ computer circuit board were implanted into the cortex, and the reference electrode into the cerebellum (Shibasaki et al., 2015). In addition, electrodes for electromyogram (EMG) were implanted into the neck muscle. The mice were then housed separately for a recovery period of at least $7 \mathrm{~d}$. After 7 d, the mice were connected to an EEG machine (EEG4214, Nihon Koden), and cortical EEG (ECoG) and EMG were recorded under freely moving conditions. The ECoG and EMG recordings were taken and matched chronologically with behaviors obtained by infrared cameras. The outputs of the ECoG and EMG were connected to a PowerLab8/30 (AD Instruments) to digitally convert the analog data. The digital EEG data were analyzed using the LabChart 8.0 software. The data were categorized into either stationary or moving conditions according to the EMG and behavioral movies. The EMG power spectrums were then calculated using the LabChart8.0 software.

Cerebellar slice electrophysiology. Parasagittal slices $(250-300 \mu \mathrm{m}$ in thickness) of the cerebellar vermis were prepared from adult mice (7-20 weeks old) as described previously (Mitsumura et al., 2011), except that cutting solution ( $\mathrm{pH}$ adjusted to 7.4 with $\mathrm{HCl}$ ) contained the following (in mM): $93 \mathrm{NMDG}, 2.5 \mathrm{KCl}, 0.5 \mathrm{CaCl}_{2}, 10 \mathrm{MgCl}_{2}, 1.25 \mathrm{NaH}_{2} \mathrm{PO}_{4}, 30$ $\mathrm{NaHCO}_{3}, 20 \mathrm{HEPES}$, and $20 \mathrm{D}$-glucose. The cerebellar slices were incubated at $32^{\circ} \mathrm{C}$ for $20-30 \mathrm{~min}$ in the above solution supplemented with sodium ascorbate ( $5 \mathrm{~mm})$, thiourea $(2 \mathrm{~mm})$, and sodium pyruvate ( $3 \mathrm{~mm}$; Zhao et al., 2011), and bubbled with $95 \% \mathrm{O}_{2}$ and $5 \% \mathrm{CO}_{2}$. The slices were then incubated at room temperature for $>1 \mathrm{~h}$ before recording in artificial CSF (ACSF), pH 7.4, consisting of the following (in mM): $125 \mathrm{NaCl}$, $2.5 \mathrm{KCl}, 2 \mathrm{CaCl}_{2}, 1 \mathrm{MgCl}_{2}, 1.25 \mathrm{NaH}_{2} \mathrm{PO}_{4}, 26 \mathrm{NaHCO}_{3}, 10$ D-glucose, bubbled with $95 \% \mathrm{O}_{2}$ and $5 \% \mathrm{CO}_{2}$, and supplemented with L-ascorbic acid $(0.4 \mathrm{~mm})$, myoinositol $(2 \mathrm{~mm})$, and sodium pyruvate $(2 \mathrm{~mm})$. Whole-cell recordings were performed at room temperature from the somata of PCs using patch pipettes (1-4 M $\Omega$ ) pulled from borosilicate glass (Harvard Apparatus) or \#0010 glass (PG10165-4, World Precision Instruments). For current-clamp recordings and outside-out patch recordings, the pipette solution, $\mathrm{pH} 7.3$, contained the following (in $\mathrm{mM}$ ): 135 potassium gluconate, $10 \mathrm{HEPES}, 5 \mathrm{KCl}, 5 \mathrm{NaCl}, 5 \mathrm{Mg}$-ATP, 0.5 Na-GTP, 0.1-0.5 EGTA, and 0-5 phosphocreatine. During recordings, picrotoxin $(100 \mu \mathrm{M})$ was added to the ACSF extracellular solution to block inhibitory synaptic transmission mediated by $\mathrm{GABA}_{\mathrm{A}}$ receptors. Membrane potential was recorded from the patched PCs in the currentclamp mode of a MultiClamp 700B amplifier (Molecular Devices) with its bridge balance and capacitance neutralization circuit. APs were evoked by injecting depolarizing current pulses from 0 to $1000 \mathrm{pA}$ in 50 pA increments every $4-8 \mathrm{~s}$. PC membrane potentials before the current injection were held at $-81 \mathrm{mV}$ to avoid spontaneous firing and minimize voltage-dependent changes in the availability of ion channels. AP occurrences were detected by a level-crossing threshold of $-25 \mathrm{mV}$. In all 
PC-excised outside-out patches, both voltage-gated $\mathrm{Na}^{+}$and $\mathrm{Ca}^{2+}$ currents were undetectable (Southan and Robertson, 2000). Spontaneous AP firing was recorded for $10-180 \mathrm{~s}$, usually soon after the formation of whole-cell recordings. The initial $10 \mathrm{~s}$ recording was used for analysis. Similar results were obtained when longer initial recording traces $(30 \mathrm{~s})$ were analyzed.

For voltage-clamp recordings of $\mathrm{Na}^{+}$currents from PCs, the pipette solution, $\mathrm{pH} 7.3$, contained the following (in mM): $125 \mathrm{CsCl}, 10$ HEPES, $5 \mathrm{Mg}$-ATP, $0.5 \mathrm{Na}$-GTP, 5 sodium phosphocreatine, 5 EGTA, 10 TEA-Cl, and five 4-aminopyridine. The recordings were made in a modified extracellular ACSF where $\mathrm{CaCl}_{2}(2 \mathrm{mM})$ and $\mathrm{MgCl}_{2}(1 \mathrm{~mm})$ were replaced with $0.1 \mathrm{mM} \mathrm{CaCl}_{2}, 3 \mathrm{mM} \mathrm{MgCl}_{2}, 0.1 \mathrm{mM} \mathrm{CdCl}_{2}, 10 \mathrm{~mm}$ TEA-Cl, and $2 \mathrm{~mm}$ 4 -aminopyridine to block both $\mathrm{K}^{+}$and $\mathrm{Ca}^{2+}$ currents. Extracellular low $\mathrm{Ca}^{2+}$ helped to minimize the contribution of unclamped dendritic $\mathrm{Ca}^{2+}$ spikes. To isolate $\mathrm{Na}^{+}$currents, leak currents were subtracted with the $\mathrm{P} / \mathrm{N}$ protocol $(\mathrm{P} / 4$ or $\mathrm{P} / 8)$ built into the pCLAMP10 software (Molecular Devices). Recorded currents were identified as $\mathrm{Na}^{+}$currents because these currents were usually abolished by application of $1 \mu \mathrm{M}$ tetrodotoxin (TTX; see Fig. 5A). In some cells, a TTX-resistant slowly developing inward current (putatively unblocked remaining distal $\mathrm{Ca}^{2+}$ currents: time to peak, $\sim 10-20 \mathrm{~ms}$ ) was observed in response to strong depolarization. Although this slow current did not interfere with the fast transient $\mathrm{Na}^{+}$current, it interfered with the slow resurgent $\mathrm{Na}^{+}$current. In such cases, the TTX-sensitive current component only was analyzed for the slow resurgent $\mathrm{Na}^{+}$current. Series resistance $(<10 \mathrm{M} \Omega$, usually 3-5 $\mathrm{M} \Omega$ ) was compensated by $\geq 80 \%$.

To determine the voltage dependency of the fast transient $\mathrm{Na}^{+}$currents activation in WT and ARF4 ${ }^{+/-} / \mathrm{ARF}^{-1-}$ PCs in cerebellar slices reliably, we used a modified three-step voltage protocol originally developed by Milescu et al. (2010), which enabled us to minimize space-clamp errors. In this protocol, a brief ( $3 \mathrm{~ms})$ mild depolarizing "pre-pulse" from -95 to $-55 \mathrm{mV}$ not substantially activating proximal $\mathrm{Na}^{+}$channels was applied to induce out-of-control distal axon-origin current spike and inactivate $\mathrm{Na}^{+}$channels in the distal neurite or axon. Then, a $2 \mathrm{~ms}$ repolarization of $-60 \mathrm{mV}$ was applied to keep the distal $\mathrm{Na}^{+}$channels inactivated and to allow partially activated proximal $\mathrm{Na}^{+}$channels to deactivate. Finally, the third pulse (ranging from -75 to $-20 \mathrm{mV}$ ) was used to measure fast transient $\mathrm{Na}^{+}$currents originating from wellclamped proximal $\mathrm{Na}^{+}$channels (Milescu et al., 2010; Bosch et al., 2015; Ransdell et al., 2017). The conductance ( $G$ ) of the fast transient $\mathrm{Na}^{+}$ currents was obtained by dividing the peak amplitude of recorded $\mathrm{Na}^{+}$ currents $\left(I_{\mathrm{Na}}\right)$ by the electrochemical driving force: $\left[G=I_{\mathrm{Na}} /\left(V-E_{\mathrm{Na}}\right)\right.$, $E_{\mathrm{Na}}=67.4 \mathrm{mV}$ (theoretically estimated); $V$ corresponds to test voltage]. $G$ was normalized to the maximal value $\left(G_{\max }\right)$ in each cell and the activation $\left(G / G_{\max }\right)$ curves were fit with the Boltzmann function, $G / G_{\max }$ $=1 /\left[1+\exp \left(V_{\text {half }}-\mathrm{V}\right) / k\right]$, where $V_{\text {half }}$ is the midpoint of activation and $k$ is the slope factor. When we examined the voltage dependence of the steady-state inactivation of the fast $\mathrm{Na}^{+}$currents, we could not use the pre-pulse protocol above (Milescu et al., 2010; Bosch et al., 2015; Ransdell et al., 2017). Therefore, 50 nм TTX was always included in the modified extracellular ACSF to reduce $\mathrm{Na}^{+}$current amplitudes and to minimize voltage-clamp errors. A long conditioning pulse (ranging from -115 to $-25 \mathrm{mV}$ ) for $200 \mathrm{~ms}$ was applied from the holding potential of $-95 \mathrm{mV}$, and then a test pulse (from the voltage of each conditioning pulse to $-20 \mathrm{mV}$ ) was applied to measure the steady-state availability of $\mathrm{Na}^{+}$channels at each conditioning pulse. The recorded $\mathrm{Na}^{+}$current amplitudes $\left(I_{\mathrm{Na}}\right)$ evoked by the test pulses were normalized to the maximal one $\left(I_{\mathrm{Na}} \max \right)$. The data were fit with the similar Boltzmann function: $I_{\mathrm{Na}} / I_{\mathrm{Na}} \max =1 /\left[1+\exp \left(V-V_{\text {half }}\right) / k\right]$.

All the electrical signals were low-pass filtered at $10 \mathrm{kHz}$ and sampled at $50 \mathrm{kHz}$ with Digidata 1440A (Molecular Devices) and the pCLAMP10 software. Only the $\mathrm{Na}^{+}$currents were recorded at a sampling frequency of $100 \mathrm{kHz}$. The liquid junction potentials were measured (14.6 and 4.7 $\mathrm{mV}$ for K-based and Cs-based intracellular solutions, respectively) and were corrected offline, except that the values of 15 and $5 \mathrm{mV}$ were used to correct voltage protocol descriptions for simplicity. Data analysis was performed using pCLAMP10 and Igor Pro (Wavemetrics) with Neuromatic (http://www.neuromatic.thinkrandom.com/; Rothman and Silver, 2018) and custom-written Igor procedures.
Behavioral tests. Mice were housed with a $12 \mathrm{~h}$ light/dark cycle, with the dark cycle occurring from 20:00 to 08:00. All mice used in the below mentioned experiments were littermates from mated heterozygotes unless otherwise noted. The experimenter was blind to the genotype in all behavioral tests.

The head shake monitoring was performed as previously described (Dursun and Handley, 1993). Eight- to 10-week-old mice were habituated to the observation cages for $60 \mathrm{~min}$ before video image recording. The test mice received saline, propranolol (10 mg/kg, i.p.), gabapentin (40 mg/kg, i.p.), benserazide (12.5 mg/kg, i.p.), L-DOPA (25 mg/kg, i.p.), and sodium valproate $(300 \mathrm{mg} / \mathrm{kg}$, i.p.). L-DOPA was administrated 20 min after benserazide injection. Head shakes during movement were counted from video recordings played at $2 \times$ slow motion. The tails of mice were fixed with piano wire, and the vibration of the piano wire was recorded by a three-axis vibration data logger (catalog \#DT-178A, Sato Shouji).

Coordination and motor skills of the mice were assessed by an accelerated rotarod test. The Rota-Rod Treadmill (Muromachi Kikai) consisted of a gridded plastic rod ( $3 \mathrm{~cm}$ in diameter, $10 \mathrm{~cm}$ long) flanked by two large round plates $(50 \mathrm{~cm}$ in diameter). The rod accelerated from 0 to 40 revolutions per minute for $3 \mathrm{~min}$ and remained at the top speed for one additional minute. Each test consisted of four trials with a $10 \mathrm{~min}$ rest between each, and the time that each mouse spent on the rod was recorded.

Antibodies. Rabbit polyclonal anti-ARF4 and anti-ARF5 antibodies were raised against mouse ARF4 (ERIQEGAAVLQKMLLEDC) and ARF5 (ERVQESADELQKMLQEDC) peptide-KLH conjugates, respectively. These were then affinity-purified against MBP-tagged full-length ARF4 and ARF5 proteins covalently coupled to CNBr-activated Sepharose $4 \mathrm{~B}$ and were subsequently used for Western blotting (1:1000) and immunocytochemistry $(1: 100)$. The following primary antibodies were used for immunohistochemistry: mouse monoclonal anti-calbindin (1: 500; catalog \#214011, Synaptic Systems); rabbit polyclonal anti-Nav1.6 (1:400; catalog \#P3088, Sigma-Aldrich); mouse monoclonal anti-panNav1 (1:4; catalog \#73-405, NeuroMab); mouse monoclonal anti-Nav1.1 (1:300; catalog \#75-023, NeuroMab); mouse monoclonal anti-Nav1.2 (1:200; catalog \#75-024, NeuroMab); mouse monoclonal anti-Kv3.3 (1: 300; catalog \#75-354, NeuroMab); mouse monoclonal anti-ankyrin-G (1:300; catalog \#75-147, NeuroMab); rabbit anti-ankyrin-G (1:500; catalog \#386003, Synaptic Systems); and rat monoclonal anti-HA (1:250; catalog \#1867423; Roche). The specificity of the Nav1.6 antibodies was tested on protein lysates from the whole brain of $\mathrm{Scn} 8 \mathrm{a}^{\mathrm{tg} / \mathrm{tg}}$ mice by Western blotting (see Fig. 8 C). The Scn8a ${ }^{\text {tg } / \mathrm{tg}} \mathrm{Nav} 1.6$ null mutation arose by nontargeted transgene insertion (Burgess et al., 1995).

Immunohistochemistry. C57BL/6J male mice were deeply anesthetized with an overdose of diethyl ether and transcardially perfused with PBS and then with Zamboni's fixative ( $2 \%$ paraformaldehyde in $0.1 \mathrm{M}$ phosphate buffer, $\mathrm{pH} 7.4$, containing $0.2 \%$ picric acid). Tissues were dissected, postfixed in Zamboni's fixative at $4^{\circ} \mathrm{C}$ for $5 \mathrm{~h}$ and cryoprotected by immersion in $15 \%$ sucrose in PBS overnight at $4^{\circ} \mathrm{C}$. After embedding in Tissue-Tek OCT compound (Sakura Finetek), tissues were frozen and sectioned at a thickness of $15 \mu \mathrm{m}$ using a cryostat (CM1950, Leica Microsystems) held at $-18^{\circ} \mathrm{C}$. The sections were air-dried for $1 \mathrm{~h}$ and rinsed in PBS three times. After blocking with 5\% bovine serum albumin (BSA) and $0.3 \%$ Triton $\mathrm{X}-100$ in PBS at room temperature for $1 \mathrm{~h}$, the sections were incubated at $4^{\circ} \mathrm{C}$ overnight with the primary antibodies in immunoreaction buffer ( $2 \times$ PBS containing $0.3 \%$ Triton X-100 and $1 \%$ BSA). The sections were then washed in PBS, incubated at room temperature for $1 \mathrm{~h}$ with the appropriate secondary antibodies in immunoreaction buffer and washed again in PBS. Stained sections were mounted in VECTASHIELD mounting medium (Vector Laboratories, Peterborough, England) and observed under a fluorescence microscope (BX51, Olympus) equipped with a CCD camera (VB-7000, Keyence). Digital images were processed using Adobe Photoshop CS5.1 software.

Production of $A A V$ Vectors. To express the ARF5 gene with a C-terminal hemagglutinin (HA) tag in PCs, we constructed the AAV vector plasmid (pAAV-L7-4-minCMV-ARF5-HA), which was designed to express ARF5 under the control of a truncated L7 promoter with a minimal cytomegalovirus sequence (minCMV; Sawada et al., 

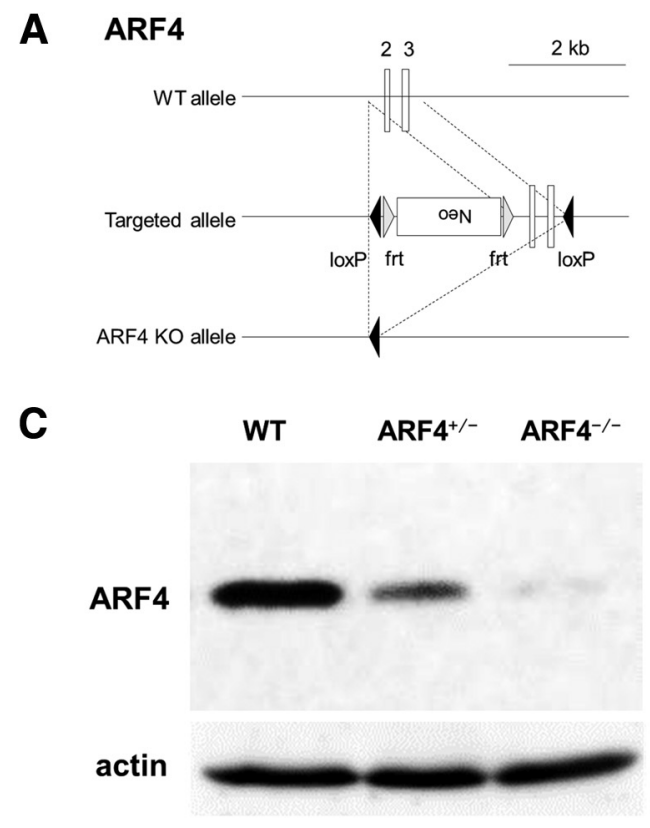

B ARF5

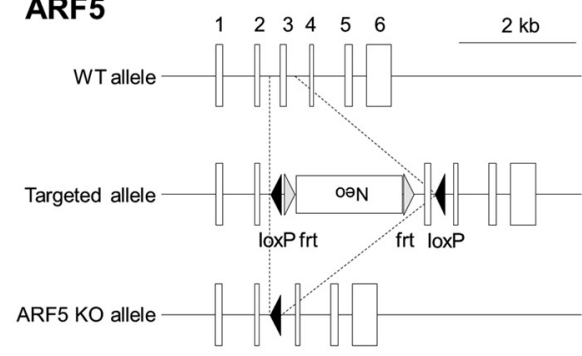

D

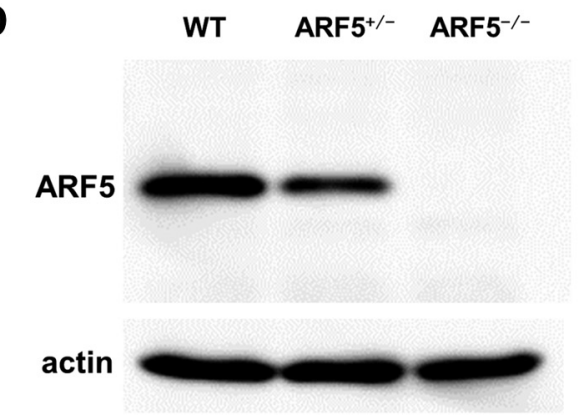

Figure 1. Generation of ARF4 ${ }^{-1-}$ and ARF5 ${ }^{-/-}$mice. $\boldsymbol{A}$, Maps of the murine ARF4 gene, both the targeted allele and the ARF4 KO allele are shown. $\boldsymbol{B}$, Maps of the murine ARF5 gene, both the targeted allele and the ARF5 $\mathrm{KO}$ allele are shown. Exons are shown as white boxes. The loxP and frt sites are depicted as black and gray arrowheads, respectively. $\boldsymbol{C}, \mathbf{D}$, Immunoblot analysis of E13.5 whole-body (ARF4) and postnatal week 8 cerebellum (ARF5) of WT (+/+), heterozygous $(+/-)$, and homozygous ( $-/-$ ) mice. Protein lysates were immunoblotted with anti-ARF4, anti-ARF5, and anti-actin antibodies.

2010). Recombinant AAV serotype 9 (AAV9) particles were generated by the cotransfection of the following three plasmids in HEK293T cells: pAAV-L7-4-minCMV-ARF5-HA, pHelper (Stratagene), and pAAV2/9 (kindly provided by Dr. J. Wilson, University of Pennsylvania, Perelman School of Medicine). The viral particles were purified by ammonium sulfate precipitation and iodixanol continuous gradient centrifugation as described previously (Miyake et al., 2012). The genomic titer of the purified AAV9 viral particles as determined by real-time PCR was $2.32 \times$ $10^{13}$ vector genomes $/ \mathrm{ml}$.

Statistical analyses. Statistical analyses were performed using the Excel Statistics (Statcel 3; Social Survey Research Information) and GraphPad Prism7 software. All data are presented as mean \pm SEM. Differences between groups were analyzed using the unpaired Student's $t$ test, oneway ANOVA followed by Scheffe post hoc test, or two-way ANOVA followed by a Holm-Sidak's post hoc test, according to each experimental design. $p<0.05$ was considered statistically significant.

\section{Results}

\section{Class II ARF-deficient mice exhibit severe} movement-associated tremors

ARF4 and ARF5 KO mice were generated as described in the Materials and Methods section (Fig. $1 A, B$ ). As previously described (Jain et al., 2012), ARF4-null homozygotes (ARF4 ${ }^{-/-}$) were embryonically lethal, whereas the heterozygotes $\left(\mathrm{ARF}^{+/-}\right.$) were viable; therefore, ARF4 ${ }^{+/-}$were used for subsequent experiments. The ARF5 KO mice generated in this study represent the first ARF5-null mice published. WT, ARF5 ${ }^{+/-}$and ARF5 ${ }^{-1-}$ pups were born at the expected 1:2:1 Mendelian frequency. Neither ARF4 nor ARF5 protein was detected in the respective $\mathrm{KO}$ mice, and a reduced amount was present in the respective heterozygous mice (Fig. 1C,D). There were no apparent significant phenotypic abnormalities in the $\mathrm{ARF} 4^{+/-}$nor the ARF5 ${ }^{-/-}$ mice.

Endogenous ARF4 and ARF5 were both widely expressed in the mouse cerebellum and could be observed in the soma and dendrites of cerebellar PCs (Fig. $2 A, B$ ). Although ARF4 ${ }^{+/-}$/ $\mathrm{ARF}^{-1-}$ and WT mice had a similar life expectancy, rotarod performance revealed that the double mutants presented motor deficits (Fig. 2 C). Interestingly, the ARF4 ${ }^{+/-} / \mathrm{ARF}^{-1-}$ mice exhibited severe tremor during movement (but not at rest) after 3-4 weeks of age (Movie 1).

We quantified tremor by measuring the frequency of head shaking during movement among the four genotypes (WT, $\mathrm{ARF}^{+/-} / \mathrm{ARF}^{+/-}, \mathrm{ARF}^{-1-}$, and ARF4 ${ }^{+/-} / \mathrm{ARF}^{-1-}$ ). Only the ARF4 ${ }^{+/-} / \mathrm{ARF}^{-1-}$ mice showed head tremor during movement (Fig. 2D). This abnormal behavior resembles the primary symptoms of ET patients and a subset of Parkinson's disease patients, and these two pathologies can be separated pharmacologically. Patients with ET can be treated to reduce their tremors with several drugs, including propranolol and gabapentin (Pahwa and Lyons, 2003). Both the head shaking frequency and body vibration exhibited by ARF4 ${ }^{+/-} / \mathrm{ARF} 5^{-1-}$ mice were decreased by administration of propranolol or gabapentin (Fig. 2E$G)$. However, L-DOPA/benserazide, effective for improving Parkinson's disease symptoms (Hwang et al., 2005); sodium valproate (NaVP), reported to improve cortical myoclonic tremor (Cen et al., 2016); benserazide alone, or saline treatment had no effect on the tremors (Fig. 2E).

\section{Class II ARF-deficient mice exhibit movement-related} abnormal brain activity and reduced excitability of cerebellar PCs

We next examined how the brain activity of ARF4 ${ }^{+/-} / \mathrm{ARF}^{-/-}$ mice was altered during movement by recording the ECoG and EMG under freely moving conditions (Fig. $3 A, B$ ). We did not find any differences in the ECoG between WT and ARF4 ${ }^{+/-}$/ $\mathrm{ARF}^{-1-}$ mice during non-moving (resting) periods (Fig. $3 A-$ $C)$. However, ECoG was dramatically changed during movement periods in ARF4 ${ }^{+/-} / \mathrm{ARF} 5^{-1-}$ mice (Fig. $3 A, B, D$ ). Analysis of ECoG power spectrums revealed a significant increase in deltawave power in moving ARF4 $4^{+/-} / \mathrm{ARF} 5^{-/-}$mice compared with WT mice (Fig. 3D). Alpha-wave and beta-wave power were also 

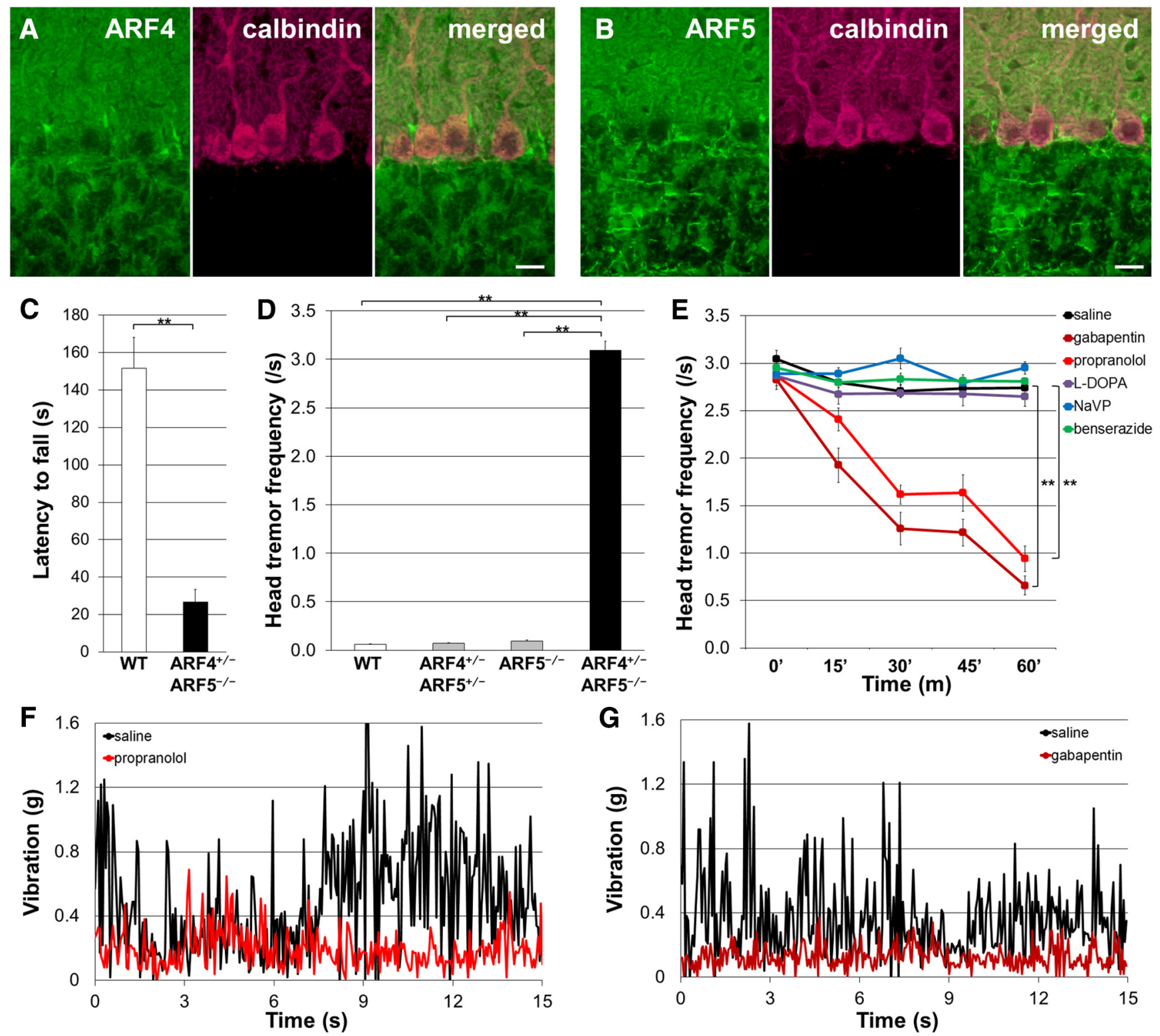

Figure 2. Treatment of ARF4 ${ }^{+/-} / \mathrm{ARF}^{-/-}$mice with propranolol and gabapentin reduced the amplitude of the pathologic tremors. $\boldsymbol{A}, \boldsymbol{B}$, Sagittal sections of WT mouse cerebella at postnatal week 8 (P8w) were immunolabeled with an anti-ARF4 (A) or anti-ARF5 (B) antibody (green) and an anti-calbindin (magenta; a PC marker) antibody. Scale bars, $20 \mu \mathrm{m}$. $\boldsymbol{C}$, Rotarod performance of WT $(n=8)$ and ARF4 ${ }^{+1-} /$ ARF5 $^{-1-}$ mice $(n=5)$ at P8W. ${ }^{* *} p<0.001$, Student's $t$ test. Error bars indicate the SEM in this figure and subsequent figures. $\boldsymbol{D}$, Head-tremor frequency of mouse during movement within 3 min was counted from video images. WT (white; $n=12$ ), ARF4 ${ }^{+/-} /$ARF5 $^{+/-}$(gray; $n=12$ ), ARF5 ${ }^{-1-}$ (gray; $n=12$ ), and ARF4 ${ }^{+/-} /$ARF5 $^{-/-}$mice (black; $n=$ 12) of P7w-P8w were used. $p<0.001$, one-way ANOVA; ${ }^{* *} p<0.001$, post hoc Scheffe's test. $\boldsymbol{E}$, Indicated drugs were administrated to the ARF4 ${ }^{+/-} /$ARF5 $^{-/-}$mice $(n=12)$. ${ }^{* *} p<0.001$ compared with controls by repeated measure ANOVA. $\boldsymbol{F}, \boldsymbol{G}$, Vibration before (black) and after ( $\boldsymbol{F}$, red; $\boldsymbol{G}$, brown) administration of propranolol $(\boldsymbol{F})$ and gabapentin $(\boldsymbol{G})$. The tail of mouse was fixed with a piano wire and the vibration of piano wire was recorded by a vibration data logger.

increased during $\mathrm{ARF} 4^{+/-} / \mathrm{ARF}^{-/-}$mice movement, while the theta-wave power was reduced (Fig. 3D). These results indicate that basal brain activities of ARF $4^{+/-} / \mathrm{ARF} 5^{-1-}$ mice were normal (Fig. 3C), but that movement triggered abnormal brain activities (Fig. 3D). We also analyzed EMG power spectrums in moving WT (Fig. $3 E$ ) and ARF $4^{+/-} / \mathrm{ARF}^{-1-}$ mice (Fig. $3 F$ ) and found that EMG median power in $\mathrm{ARF} 4^{+/-} / \mathrm{ARF} 5^{-/-}$mice was significantly different from that in WT mice. In our study, the electrodes for ECoG were implanted into the cerebrum, and the reference electrode into the cerebellum (Shibasaki et al., 2015). This recording configuration would mean that the ECoG in our hands reflects differential neuronal activities between the cerebrum and the cerebellum. Therefore, it is possible that the abnor- mality of ECoG (Fig. $3 A-D$ ) in ARF4 ${ }^{+/-} / \mathrm{ARF} 5^{-1-}$ mice arises from the abnormal neuronal activity in the cerebellum.

Next, we recorded AP firing in cerebellar PCs using acute slice preparations in ARF4 $4^{+/-} / \mathrm{ARF}^{-/-}$mice. Injection of depolarizing currents smaller than $600 \mathrm{pA}$ evoked similar AP firing between WT and ARF4 ${ }^{+/-} /$ARF5 $^{-/-}$mice (Fig. $4 A, B$ ). However, injection of larger depolarizing currents resulted in much fewer spike discharges in ARF4 ${ }^{+/-} / \mathrm{ARF}^{-/-}$mice (Fig. $4 A, B$ ). At 400 pA current injection, spike discharge was continuous both in WT and ARF4 ${ }^{+/-} / \mathrm{ARF}^{-1-}$ mice (Fig. $4 A$, left), but at a larger current injection $(800 \mathrm{pA}), \mathrm{ARF} 4^{+/-} / \mathrm{ARF} 5^{-/-}$mice tended to show a strong adaptation during AP firing and a large depolarization plateau after AP burst (Fig. $4 A$, right, bottom). To quantify this 


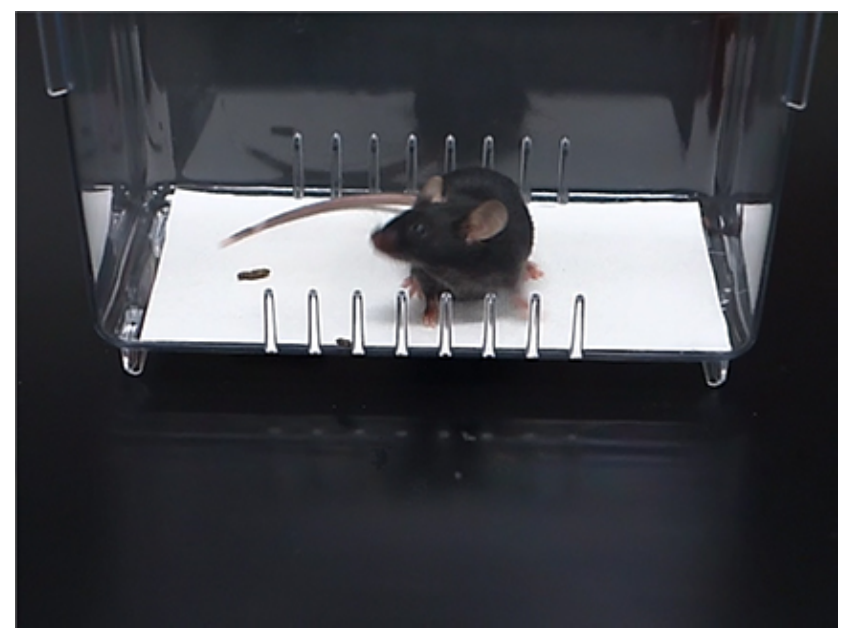

Movie 1. ET-like behaviors of an ARF4 ${ }^{+/-} /$ARF $^{-/-}$adult (postnatal week 8) male mouse. Tremor-like head shaking occurs only during locomotion, but not at rest. phenomenon, we measured AP train duration (time from the first AP event to the last AP event) both at smaller (400 pA) and larger $(800 \mathrm{pA})$ current injections. There was no significant difference between WT and ARF4 $4^{+/-} / \mathrm{ARF}^{-1-}$ mice at $400 \mathrm{pA}$ injection (Fig. $4 C$; WT, $373.1 \pm 31.9 \mathrm{~ms}, n=29$; $\mathrm{ARF}^{+/-}$/ $\left.\mathrm{ARF}^{-1-}, 340.8 \pm 35.3 \mathrm{~ms}, n=31, p=0.500\right)$. However, at 800 pA injection, AP train duration was significantly shorter in $\mathrm{ARF}^{+/-}{ }^{+\mathrm{ARF}^{-/-}}{ }^{\text {mice }}$ (Fig, $4 C$; WT, $301.6 \pm 36.2 \mathrm{~ms}, n=33$; $\mathrm{ARF}^{+/-}$/ARF5 $\left.^{-/-}, 142.9 \pm 27.6 \mathrm{~ms}, n=32, p=0.001\right)$. We also measured mean interspike intervals at 400 and 800 pA current injections, and no significant difference was observed between WT and ARF4 ${ }^{+/-} / \mathrm{ARF}^{-/-}$mice (Fig. $4 D ; 400 \mathrm{pA}$ injection, WT, $13.07 \pm 1.45 \mathrm{~ms}, n=29$; $\mathrm{ARF}^{+/-} / \mathrm{ARF}^{-1-}$, $10.87 \pm 0.97 \mathrm{~ms}, n=31, p=0.207 ; 800 \mathrm{pA}$ injection, WT, $7.61 \pm$ $0.71 \mathrm{~ms}, n=33$ ARF $4 ~^{+/-} / \mathrm{ARF}^{-1-}, 6.00 \pm 0.52 \mathrm{~ms}, n=32, p=$ $0.221)$. These results indicate that the total number of evoked APs is reduced (Fig. $4 B$ ) without any change in AP firing frequency (i.e., the inverse of interspike interval; Fig. 4D). To examine AP adaptation during repetitive firing in WT and $\mathrm{ARF} 4^{+/-}$, $\mathrm{ARF}^{-1-}$ mice, we measured AP amplitude (the amplitude from the threshold potential where its derivative exceeds $20 \mathrm{mV} / \mathrm{ms}$, to the peak of the AP) during repetitive firing at the smaller and the larger current injections (Fig. $4 E$ ). There was no significant difference in AP amplitude at the smaller current injection (400 pA), but AP amplitude later in the AP firing sequence (later than the
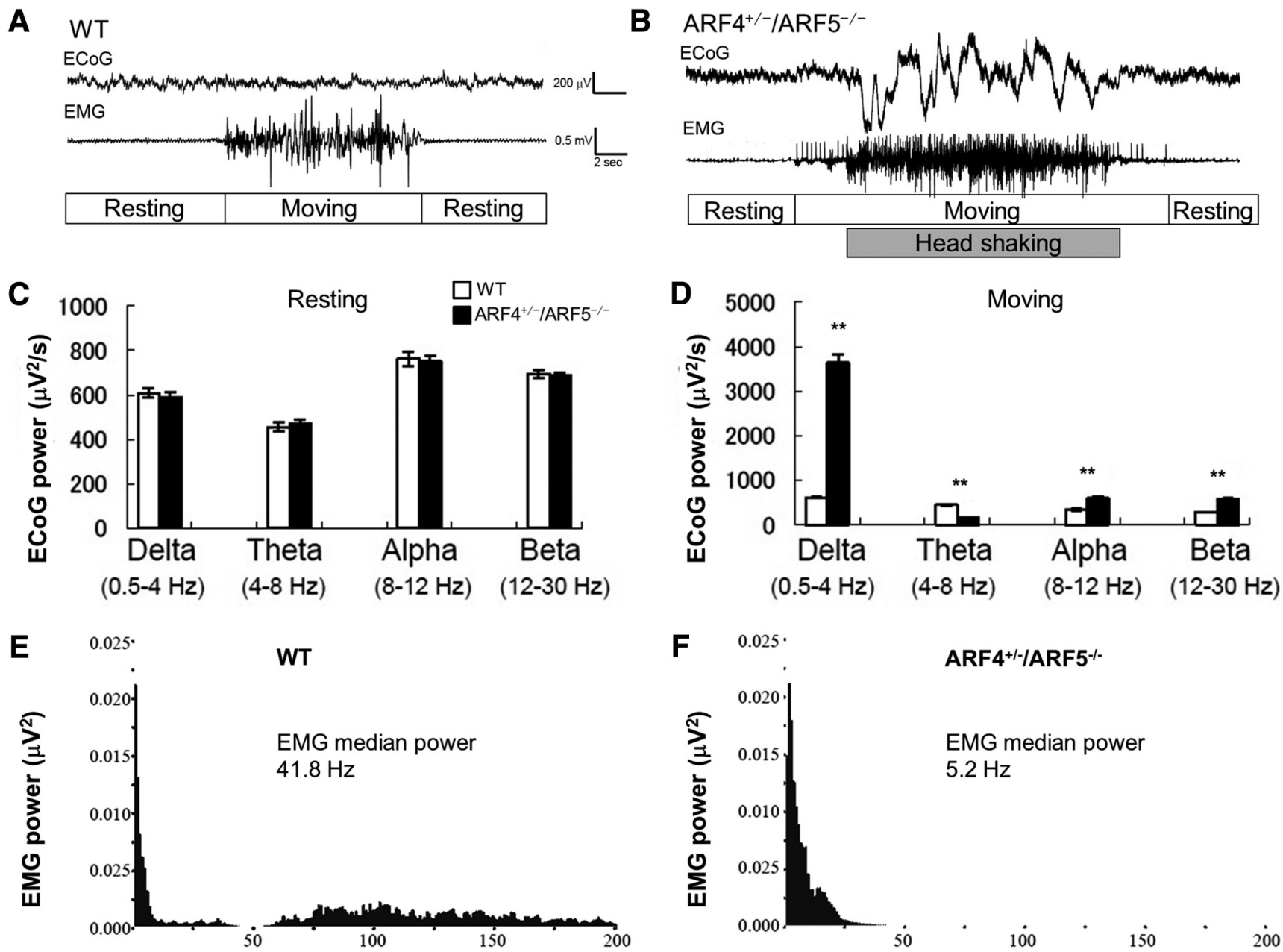
$150 \quad 200$

Figure 3. Abnormal ECOG and EMG activities in ARF $4^{+/-} / \mathrm{ARF}^{-1-}$ mice upon moving periods. $\boldsymbol{A}, \boldsymbol{B}$, Representative ECoG and EMG traces in WT $(\boldsymbol{A})$ or ARF $4^{+/-} / \mathrm{ARF}^{-/-}(\boldsymbol{B})$ mice upon wakefulness. $C, D, E C O G$ power spectrums were quantified in non-moving, resting mice $(\boldsymbol{C})$ and moving $(\boldsymbol{D})$ mice upon wakefulness. ${ }^{* *} p<0.001$, Student's t test (WT vs ARF4 ${ }^{+/-} /$ARF5 $^{-/-}, n=$ 6 each, $t$ test). $\boldsymbol{E}, \boldsymbol{F}$, A representative EMG power spectrum was calculated in moving WT $(\boldsymbol{E})$ or ARF4 ${ }^{+/-} /$ARF5 $^{-1-}(\boldsymbol{F})$ mouse upon wakefulness. 
A

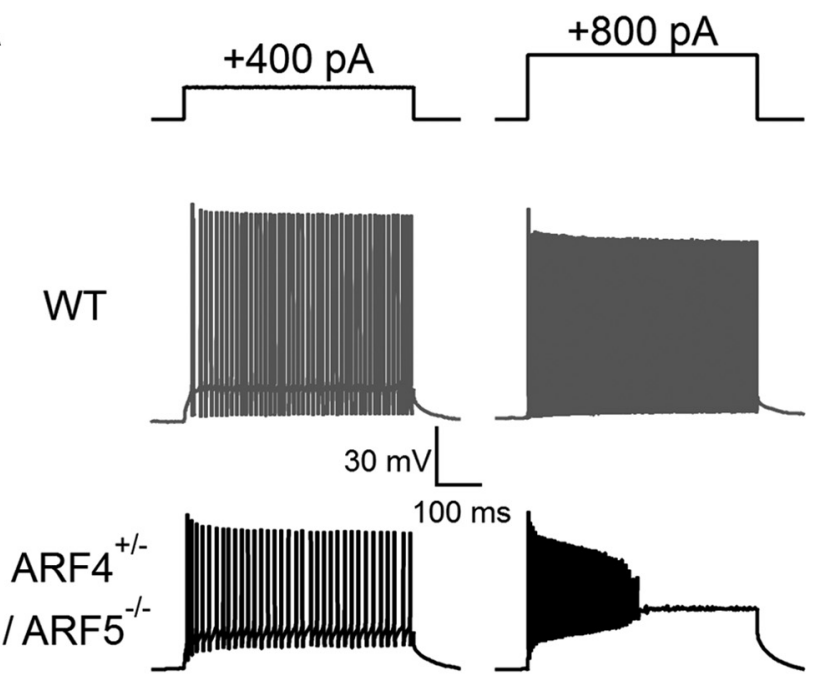

C

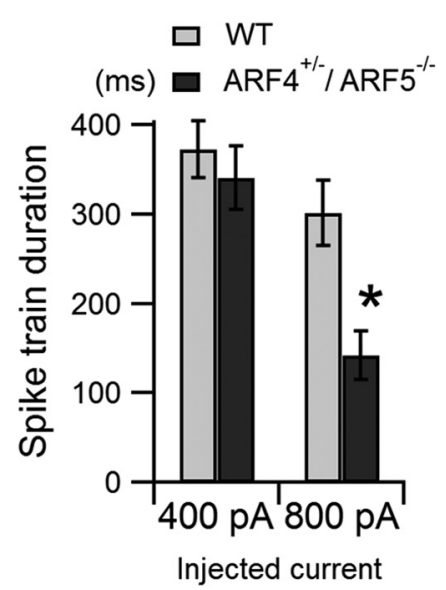

F

(\%)

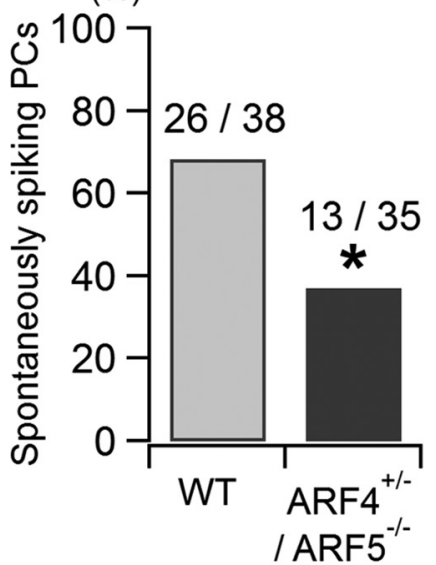

G
B

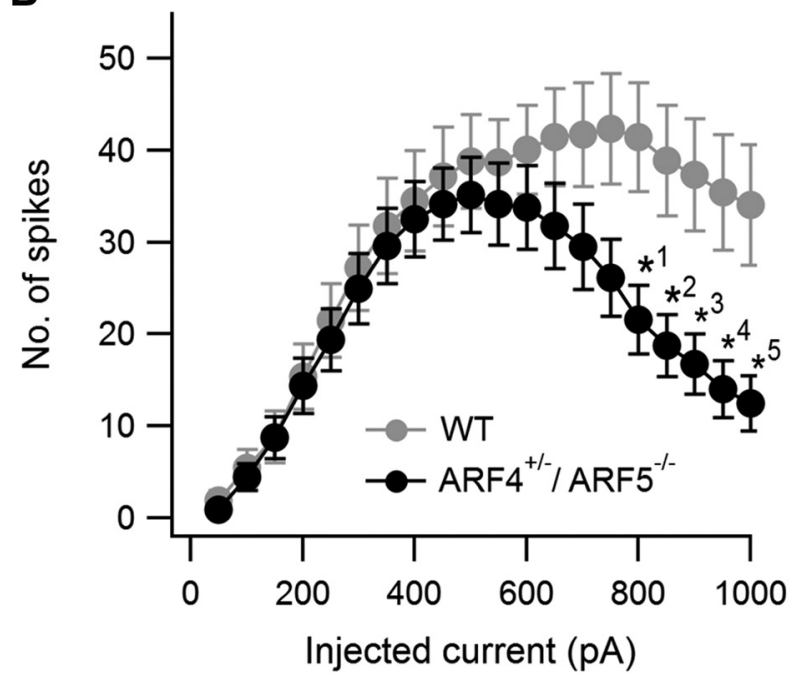

E

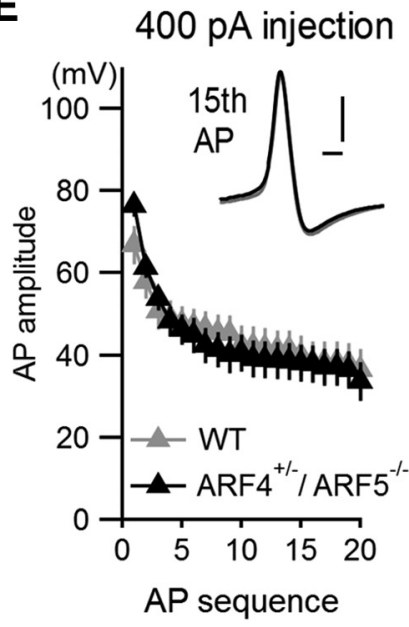

WT
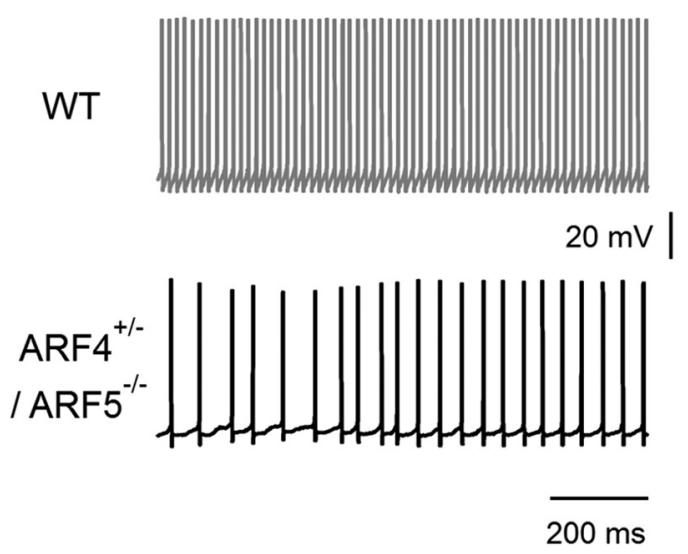

( $\mathrm{Hz})$

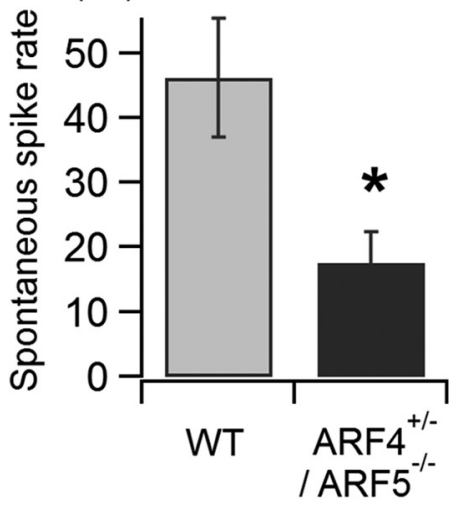

Figure 4. Reduced intrinsic excitability and abnormal spontaneous firing activity of cerebellar PCs in ARF4 ${ }^{+/-} /$ARF ${ }^{-/-}$mice. $\boldsymbol{A}$, Representative traces of AP firing in response to smaller (left; 400 pA injection) and larger (right; 800 pA injection) depolarizing current injections ( $500 \mathrm{~ms}$ ) in WT (gray) and ARF4 ${ }^{+/-} /$ARF $^{-1-}$ (black) PCs. B, The average number of evoked APs plotted against the injected current amplitudes in WT (gray; $n=33$ ) and ARF4 ${ }^{+/-} /$ARF5 $^{-1-}$ (black; $n=32$ ) PCs. The data were collected from more than six mice in each condition. A repeated-measures two-way ANOVA indicates a significant interaction (genotype $\times$ injected current; $F(19,1197)=3.42 ; p<0.0001$ ). Multiple-comparison tests with Holm-Sidak's method show significant differences between WT and ARF4 ${ }^{+1-} /$ ARF5 $^{-1-}$ at injected current strength indicated by: ${ }^{* 1} p=0.0249,{ }^{* 2} p=0.0221,{ }^{* 3} p=0.0176,{ }^{* 4} p=0.0121,{ }^{* 5} p=0.0111$. C, $\boldsymbol{D}$, Respective pooled data of spike-train duration (ms) and interspike intervals (ms) at smaller $400 \mathrm{pA}$ injection and larger $800 \mathrm{pA}$ current injection. Spike-train duration was defined as the time difference between the first and the last AP events at each current injection. The interspike interval was measured as the mean of intervals between adjacent spike events at each current injection. ${ }^{*} p<0.005$ between WT and ARF4 ${ }^{+1-} /$ ARF5 $^{-1-}$ mice at $800 \mathrm{pA}$ injection, Student's $t$ test with multiple test correction. $E$, Pooled data of AP amplitudes at smaller $400 \mathrm{pA}$ injection (left) and larger $800 \mathrm{pA}$ current injection (right). Insets show the 15 th AP waveforms ( gray, WT; black, ARF4 ${ }^{+/-} / \mathrm{ARF}^{-/-}$) aligned with the AP threshold time points at which their differentiated waveform (dV/dt) exceeded $20 \mathrm{mV} / \mathrm{ms.}$ Horizontal and vertical scale bars in insets correspond to $0.5 \mathrm{~ms}$ and $20 \mathrm{mV}$, respectively. AP amplitude was measured from the threshold potential to the positive (Figure legend continues.) 


\begin{tabular}{|c|c|c|c|}
\hline & WT & $\mathrm{ARF}^{+1-}{ }^{+\mathrm{ARF}^{-1-}}$ & $t$ test results \\
\hline \multicolumn{4}{|l|}{ AP parameters } \\
\hline & $n=35$ & $n=33$ & \\
\hline AP peak, mV & $14.7 \pm 1.4$ & $11.3 \pm 1.7$ & $p=0.102$ \\
\hline Maximum rate of rise, $\mathrm{mV} / \mathrm{ms}$ & $390.3 \pm 17.7$ & $363.8 \pm 15.3$ & $p=0.194$ \\
\hline Maximum rate of fall, $\mathrm{mV} / \mathrm{ms}$ & $-260.6 \pm 14.2$ & $-237.6 \pm 11.9$ & $p=0.223$ \\
\hline AP threshold, mV & $-58.1 \pm 0.9$ & $-59.4 \pm 1.1$ & $p=0.295$ \\
\hline AP half-amplitude width, ms & $0.36 \pm 0.02$ & $0.37 \pm 0.01$ & $p=0.630$ \\
\hline AP afterhyperpolarization peak, $\mathrm{mV}$ & $-72.6 \pm 0.9$ & $-73.8 \pm 1.0$ & $p=0.190$ \\
\hline $\begin{array}{l}\text { Adjusted membrane potential } \\
(\mathrm{mV}) \text { before current pulses }\end{array}$ & $-81.1 \pm 0.38$ & $-81.4 \pm 0.40$ & $p=0.578$ \\
\hline \multicolumn{4}{|l|}{ Passive electrical properties } \\
\hline & $n=38$ & $n=30$ & \\
\hline Membrane capacitance, pF & $552.1 \pm 45.6$ & $512.3 \pm 46.8$ & $p=0.545$ \\
\hline Input resistance, $\mathrm{M} \Omega$ & $239.2 \pm 32.9$ & $272.3 \pm 36.7$ & $p=0.504$ \\
\hline
\end{tabular}

The first APs evoked by the smallest injected currents (i.e., threshold currents) were analyzed to estimate AP waveform parameters. To even out voltage-dependent effects on ion channel states before current pulses, $\mathrm{PC}$ membrane potential was always set to $-81 \mathrm{mV}$, and we confirmed that there was no significant difference between WT and ARF $4^{+1-} /$ ARF5 $^{-1-}$ mice. Maximum rates of rise and fall in each AP were measured by detecting positive and negative peak values of its differentiated waveform (dV/dt), respectively. The AP threshold was defined as the membrane potential at which $\mathrm{dV} / \mathrm{dt}$ exceeded $20 \mathrm{mV} / \mathrm{ms}$. AP half-amplitude width was defined as the width at the midpoint between the threshold and the peak of its AP. The passive electrical properties of $\mathrm{PC} C$ were estimated using averaged traces of $\sim 20$ current responses evoked by hyperpolarizing voltage pulses (from -85 to $-90 \mathrm{mV}, 500 \mathrm{~ms}$ duration) in a voltage-clamp mode.

8th AP) was significantly smaller in ARF4 ${ }^{+/-} / \mathrm{ARF}^{-/-}$mice at the larger current injection ( $800 \mathrm{pA}$; Fig, $4 E$ ). These data indicate that the PC intrinsic excitability is indeed reduced in the case of larger current inputs in $\mathrm{ARF} 4^{+/-} / \mathrm{ARF} 5^{-1-}$ mice. We also examined the parameters of the first AP waveforms evoked by the minimum currents (the threshold currents) in WT and ARF $4^{+/-}$/ $\mathrm{ARF}^{-1-}$ PCs. In this experimental condition, availability of voltage-gated $\mathrm{Na}^{+}$and other ion channels was considered almost constant before the current injection, because membrane potential of PCs before the current pulses was always set to $-81 \mathrm{mV}$ (Table 1). We found no significant differences in any parameters, such as AP peak, maximum rate of rise, maximum rate of fall, AP threshold, AP half-width, and AP after-hyperpolarization peak (minimum voltage of AP), between WT and ARF $4^{+/-} / \mathrm{ARF}^{-1-}$ mice (Table 1). The passive electrical properties of PCs, which may affect AP output (Bekkers and Häusser, 2007), were similar between WT and ARF4 ${ }^{+/-} / \mathrm{ARF}^{-1-}$ mice (Table 1). Furthermore, spontaneous AP firing was examined, and the percentage of spontaneous spiking PCs was significantly smaller in ARF4 ${ }^{+/-}$/ ARF5 $^{-1-}$ mice $(37.1 \%, 13$ of 35 recorded cells) than in WT mice (68.4\%, 26 of 38 recorded cells; Fig. 4F, Fischer's exact test, $p=$ $0.010)$. Spontaneous spike rate was significantly smaller in $\mathrm{ARF}^{+/-} / \mathrm{ARF}^{-/-}$mice than WT (Fig. $4 G$; WT, $46.18 \pm 9.19$ $\mathrm{Hz}, n=38$ ARF $^{+/-}$/ARF5 $^{-/-}, 17.65 \pm 4.84 \mathrm{~Hz}, n=35, p=$ $0.027)$. These results suggest that active conductances, mediated by voltage-gated $\mathrm{Na}^{+}$or other ion channels, may be altered in ARF $4^{+/-} / \mathrm{ARF}^{-1-}$ PCs.

\section{$\leftarrow$}

(Figure legend continued.) peak of each AP. Multiple-comparison tests show significant differences between WT and ARF4 ${ }^{+/-} /$ARF5 $^{-1-}$ from the 8th to 15 th AP amplitudes $\left({ }^{*} p<\right.$ $0.05)$ at $800 \mathrm{pA}$ larger current injection, but not at $400 \mathrm{pA}$ smaller current injection. $\boldsymbol{F}$, Percentage of spontaneously active (i.e., spiking) PCs out of all the recorded PCs. Fischer's exact test indicates that the fraction of spontaneously active $\mathrm{PCs}$ is significantly smaller in ARF4 ${ }^{+/-}$, ARF5 $^{-1-}$ mice compared with WT $\left({ }^{*} p=0.0101\right) . G$, Representative traces of spontaneously fired APs in WT (left, top, gray) and ARF4 ${ }^{+1-} /$ ARF5 $^{-1-}$ (left, bottom, black) PCs. Right, Mean spontaneous spike rates in WT (gray) and ARF $4^{+/-} /$ARF5 $^{-1-}$ (black) PCs. ${ }^{*} p=0.0273$, Student's $t$ test.
To explore the mechanism of the reduced intrinsic excitability, we examined the amplitude of transient $\mathrm{Na}^{+}$currents underlying AP generation in WT and ARF4 ${ }^{+/-} / \mathrm{ARF}^{-/-}$PCs. The fast transient $\mathrm{Na}^{+}$currents were evoked by a depolarizing pulse from -95 to $+25 \mathrm{mV}$ (Fig. 5A). The recorded currents were identified as $\mathrm{Na}^{+}$current because addition of $1 \mu \mathrm{M}$ TTX always abolished the currents (Fig. 5A, red). The amplitude of the transient $\mathrm{Na}^{+}$ currents was significantly reduced in $\mathrm{ARF} 4^{+/-} / \mathrm{ARF}^{-/-} \mathrm{PCs}$ ( $\sim 34 \%$ reduction) compared with WT PCs (Fig. 5B; WT, $-10.04 \pm 0.81 \mathrm{nA}, n=11 ; \mathrm{ARF}^{+/-}{ }^{+\mathrm{ARF}^{-/-}}{ }^{-6.69 \pm 1.01}$ $\mathrm{nA}, n=11 ; p<0.05)$. However, there was no difference in the voltage dependence of the transient $\mathrm{Na}^{+}$current activation, measured with a modified three-step voltage protocol (Fig. 5C; see Materials and Methods; Milescu et al., 2010; Bosch et al., 2015; Ransdell et al., 2017), between WT and ARF4 ${ }^{+/-} / \mathrm{ARF}^{-1-}$ PCs (Fig. 5D). The midpoint of activation and slope factor were similar in PCs from WT mice ( $V_{\text {half }}=-47.3 \pm 1.5 \mathrm{mV}, k=3.9 \pm$ $0.3, n=10)$ and ARF4 ${ }^{+/-} /$ARF5 $^{-1-}$ mice $\left(V_{\text {half }}=-46.8 \pm 1.6\right.$ $\mathrm{mV}, k=3.3 \pm 0.4, n=11 ; t$ test of $V_{\text {half }}$ and $k, p=0.827, p=$ 0.207 , respectively). Next, we examined the voltage dependence of steady-state inactivation of the transient $\mathrm{Na}^{+}$currents using a $200 \mathrm{~ms}$ conditioning pulse combined with a $10 \mathrm{~ms}$ test pulse to $-25 \mathrm{mV}$ (Fig. 5E). The voltage dependence of the transient $\mathrm{Na}^{+}$ current inactivation was similar between WT and ARF4 ${ }^{+/-}$, ARF5 $^{-1-}$ PCs (Fig. 5F; WT, $V_{\text {half }}=-69.3 \pm 0.7 \mathrm{mV}, k=5.7 \pm$ $0.2, n=13$; ARF4 ${ }^{+/-} / \mathrm{ARF}^{-l-}, V_{\text {half }}=-70.0 \pm 1.0 \mathrm{mV}, k=$ $6.26 \pm 0.3, n=9 ; t$ test of $V_{\text {half }}$ and $k, p=0.577, p=0.075$, respectively). These results suggest that the amplitude of the $\mathrm{Na}^{+}$ current is reduced with no alteration in its activation property nor its inactivation property in ARF4 $4^{+/-} / \mathrm{ARF}^{-/-} \mathrm{PCs}$.

\section{Class II ARF-deficient mice exhibit selective depletion of Nav1.6 proteins in the AIS of PCs}

Cerebellar PCs have two types of pore-forming $\alpha$ subunits (Nav1.1 and Nav1.6) in their voltage-gated sodium channels, which are responsible for AP initiation and propagation (Schaller and Caldwell, 2003). Similar to $\mathrm{ARF} 4^{+/-} / \mathrm{ARF}^{-/-}$mice, Nav1.6-deficient mice exhibit ataxia, tremor, and reduced AP firing in PCs (Meisler and Kearney, 2005; Levin et al., 2006). We therefore performed immunohistochemical analysis of Nav1.6 expression in ARF4 $4^{+/-} / \mathrm{ARF}^{-/-}$mice. Nav1.6 expression in the AIS was severely decreased in ARF4 ${ }^{+/-} / \mathrm{ARF}^{-/-} \mathrm{PCs}$ (Fig. $6 A-$ C). Nav1.6 is one of the primary determinants of the resurgent $\mathrm{Na}^{+}$current in PCs (Raman et al., 1997), which plays a critical role in repetitive firing in PCs (Lewis and Raman, 2014; Ransdell and Nerbonne, 2018). The resurgent $\mathrm{Na}^{+}$current flows through the same $\mathrm{Na}^{+}$channels as the transient $\mathrm{Na}^{+}$current, but it is activated by repolarization after $\mathrm{Na}^{+}$channel inactivation with distinct slower kinetics and voltage dependence in PCs (Lewis and Raman, 2014; Ransdell and Nerbonne, 2018). Thus, we also examined whether the resurgent $\mathrm{Na}^{+}$current component is reduced in ARF4 ${ }^{+/-} / \mathrm{ARF}^{-1-}$ PCs. Using a brief depolarizing voltage pulse to $+25 \mathrm{mV}$, to activate and inactivate $\mathrm{Na}^{+}$channels, followed by a repolarizing test pulse to various voltages $(-75$ to $-5 \mathrm{mV})$, and a modified ACSF solution with $\mathrm{K}^{+}$and $\mathrm{Ca}^{2+}$ channel blockers, we managed to measure resurgent $\mathrm{Na}^{+}$ currents that were blocked by $1 \mu \mathrm{M}$ TTX (Fig. 6D; Ransdell et al., 2017; Valkova et al., 2017). As expected, the resurgent $\mathrm{Na}^{+}$currents were significantly smaller in ARF $4^{+/-} / \mathrm{ARF} 5^{-1-}$ PCs than in WT PCs (Fig. 6E). The results above indicate that Nav1.6 in the AIS of PCs is clearly decreased anatomically and functionally in $\mathrm{ARF}^{+/-} / \mathrm{ARF}^{-1-}$ mice. 
A
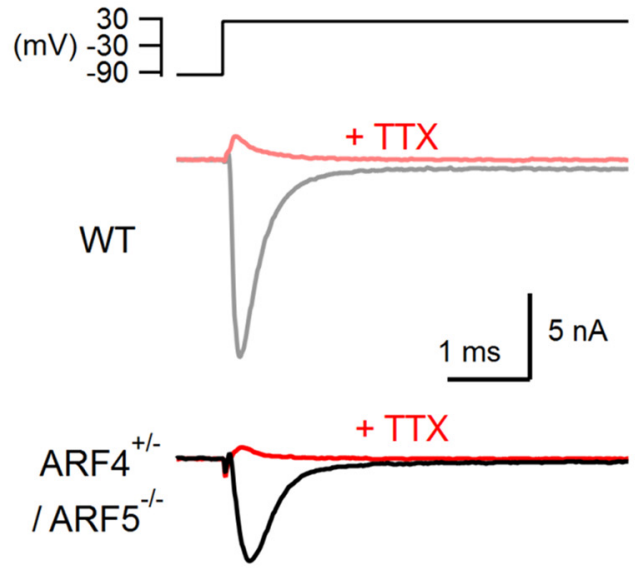

C
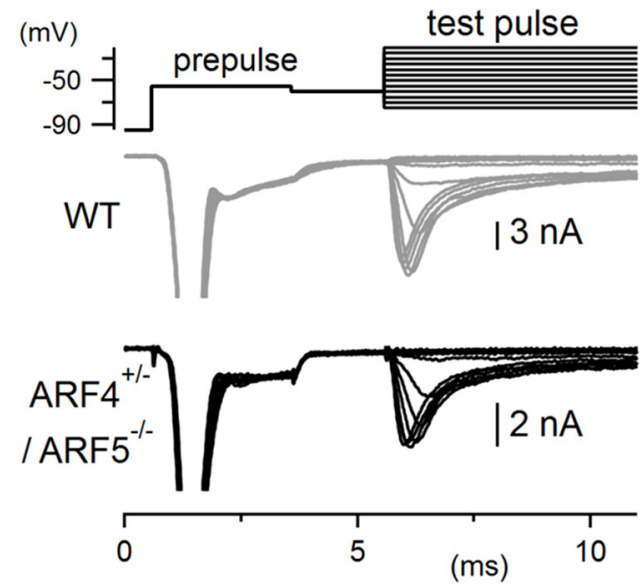

E

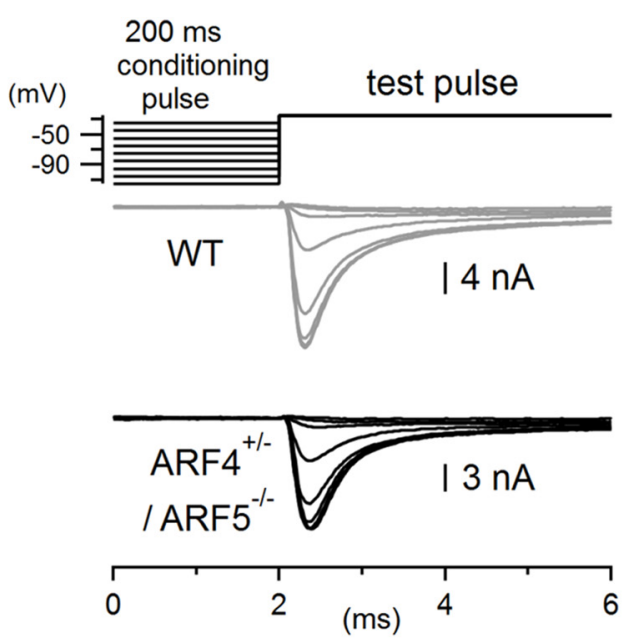

B

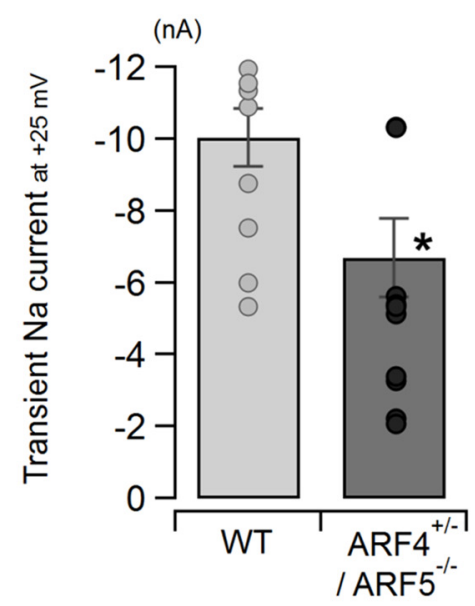

D

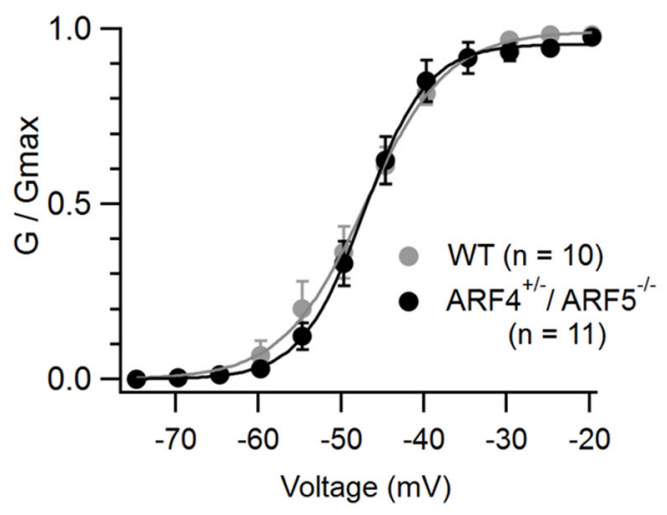

$\mathbf{F}$

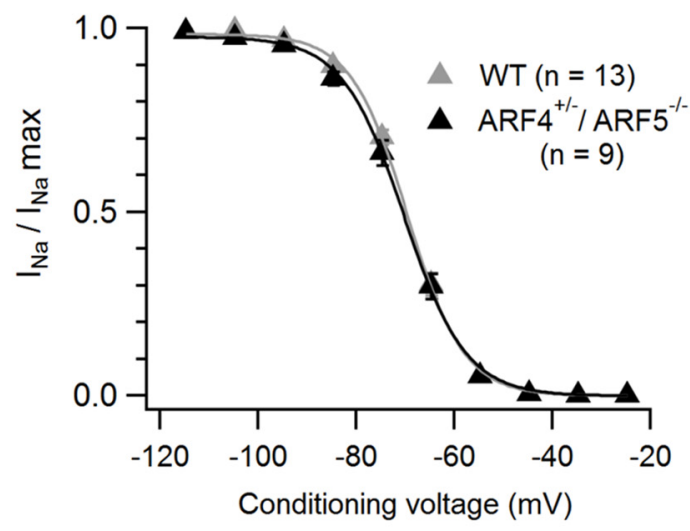

Figure 5. Reduced fast transient $\mathrm{Na}^{+}$currents with no change in activation or inactivation properties in cerebellar ARF $4^{+/-} / \mathrm{ARF}^{-/-} \mathrm{PCs}$. $\boldsymbol{A}$, Representative traces of fast transient Na ${ }^{+}$ currents evoked by a depolarizing voltage pulse from $-95 \mathrm{mV}$ to $+25 \mathrm{mV}$ in WT (gray) and ARF4 ${ }^{+/-} / \mathrm{ARF}^{-1-}$ (black) PCs. The recorded currents were abolished by extracellular application of $1 \mu \mathrm{M} \mathrm{TTX}, \mathrm{Na}^{+}$channel blocker (red). B, Pooled data of peak amplitudes of the fast transient $\mathrm{Na}^{+}$currents recorded at $+25 \mathrm{mV}$ as described in $\boldsymbol{A}$. Bar graphs show mean values, and symbols represent individual data points. ${ }^{*} p<0.05$, Student's $t$ test. $C$, Representative traces used in the analysis of voltage dependence of transient $\mathrm{Na}^{+}$current activation (test pulses ranging from -75 $\mathrm{mV}$ to $-15 \mathrm{mV}$ in $5 \mathrm{mV}$ increments) recorded from PCs in cerebellar slices. A pre-pulse of $-55 \mathrm{mV}$ (subthreshold for proximal $\mathrm{Na}^{+}$channels) was applied before test pulses to elicit unclamped axonal $\mathrm{Na}^{+}$spikes and inactivate distal $\mathrm{Na}^{+}$channels, leaving well controlled proximal $\mathrm{Na}^{+}$channels available for the upcoming test pulses. $\boldsymbol{D}$, Normalized conductance-voltage relations for the fast transient $\mathrm{Na}^{+}$currents in response to the test pulses shown in $C$ in WT (gray) and ARF4 ${ }^{+/-} / \mathrm{ARF}^{-1-}$ (black) PCs. The activation $\left(G / G_{\text {max }}\right.$ ) curves were fit with Boltzmann functions (see Materials and Methods). The voltage dependency of the transient $\mathrm{Na}^{+}$current activation is similar between WT and ARF $4^{+1-} / \mathrm{ARF} 5^{-1-} \mathrm{PC}$. $\boldsymbol{E}$, Representative traces used in the analysis of voltage-dependent steady-state inactivation of $\mathrm{Na}^{+}$currents. Conditioning voltage pulses ( $200 \mathrm{~ms}$, ranging from $-115 \mathrm{mV}$ to $-25 \mathrm{mV}$ in $10 \mathrm{mV}$ steps) were applied to determine the voltage dependence of steady-state inactivation before a $10 \mathrm{~ms}$ test pulse to $-25 \mathrm{mV}$. F, Steady-state inactivation curve for the fast transient $\mathrm{Na}^{+}$currents. Normalized $\mathrm{Na}^{+}$currents $\left(I_{\mathrm{Na}} / I_{\mathrm{Na}} \mathrm{max}\right)$ evoked by test pulses were plotted against conditioning voltages. Data were fit with Boltzmann functions (see Materials and Methods). 

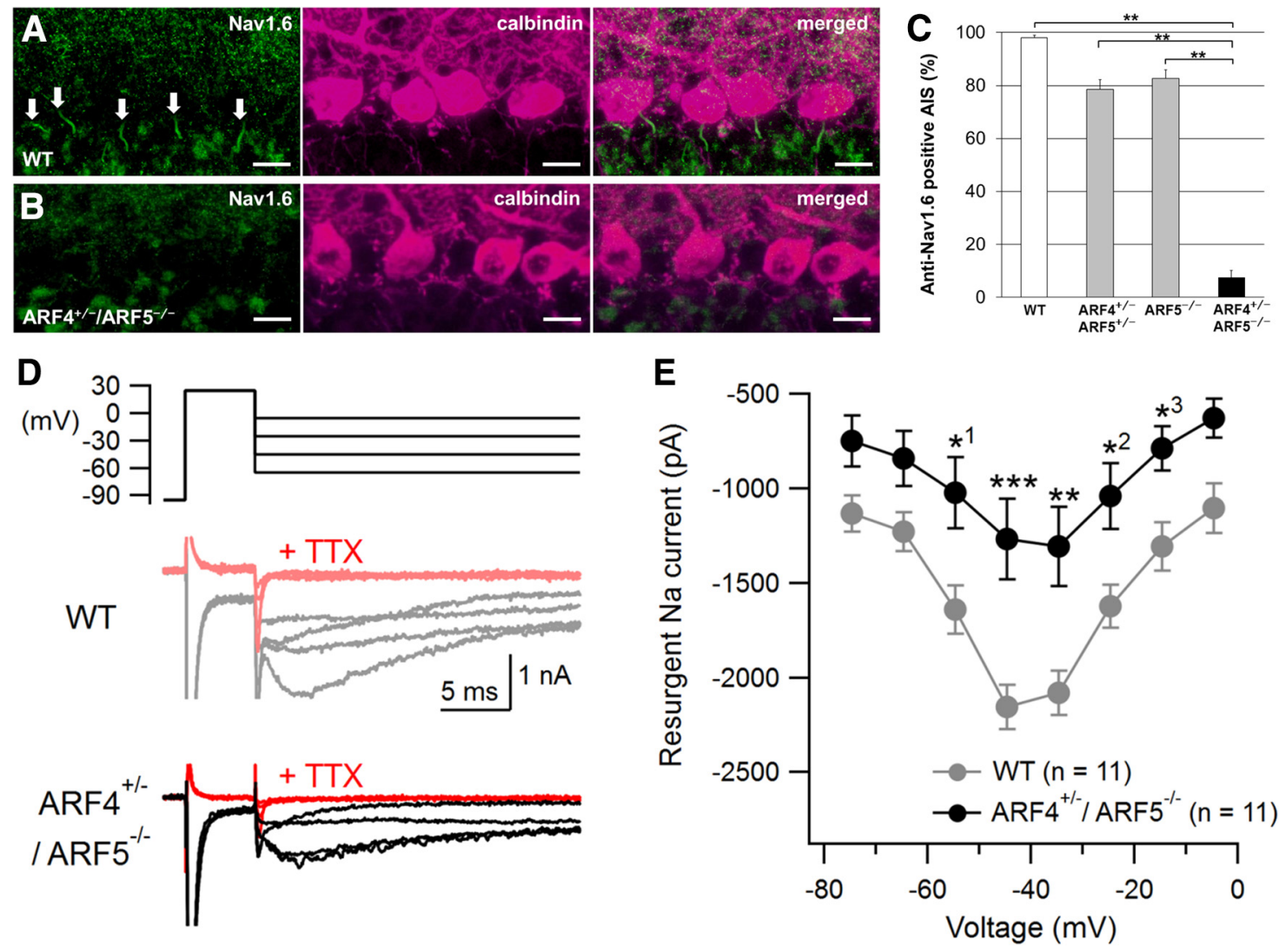

Figure 6. Reduced Nav1.6 localization to the AIS of PCs and reduced resurgent Na ${ }^{+}$currents in ARF $4^{+/-} /$ARF $^{-1-}$ PCs. $\boldsymbol{A}, \boldsymbol{B}$, Sagittal sections of postnatal week 8 (P8w) WT (A) and ARF4 ${ }^{+/-} /$ARF5 $^{-I-}(B)$ mouse cerebella were immunolabeled with an anti-Nav1.6 antibody (green) and an anti-calbindin (magenta) antibody. White arrows indicate Nav1.6 immunoreactivities in the AIS of PCS. Scale bars, $20 \mu \mathrm{m}$. C, The proportion of Nav1.6-positive AISs to ankyrin-G-positive AISs in WT (white; $n=41)$, ARF4 $^{+/-} /$ARF5 $^{+/-}$(gray; $n=23$ ), ARF5 ${ }^{-/-}$(gray; $n=37$ ), and ARF4 $^{+/-} /$ARF5 $^{-1-}$ PCs (black; $\left.n=18\right)$ at P8w. $p<0.001$, one-way ANOVA; ${ }^{* *} p<0.001$, post hoc Scheffe's test. $D$, Representative traces of resurgent $\mathrm{Na}^{+}$currents evoked by repolarizing test pulses $\left(-65,-45,-25\right.$, and $-5 \mathrm{mV}$ ) following a 5 ms voltage step to $+25 \mathrm{mV}$ in WT (gray) and ARF4 ${ }^{+/-} /$ARF5 $^{-1-}$ (black) PCs. The resurgent currents in response to the test pulses (as well

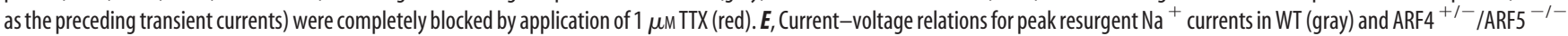
(black) PCs. A repeated-measures two-way ANOVA indicates significant genotype effect $\left(F_{(1,20)}=9.881 ; p<0.01\right)$ and interaction (genotype $\times$ voltage; $\left.F_{(7,140)}=3.789 ; p<0.001\right)$. Multiple-comparison tests with Holm-Sidak's method show significant differences between WT and ARF4 ${ }^{+/-} /$ARF5 $^{-1-}$ at voltage values indicated by: ${ }^{* 1} p=0.0167,{ }^{* 2} p=0.0233,{ }^{* 3} p=$ $0.0473,{ }^{* *} p=0.0014$, and ${ }^{* * *} p=0.0002$.

On the other hand, there was no significant difference in the density of Nav1.6 puncta in the dendrites or the soma (Fig. $7 A-D$ ) of PCs between WT and ARF4 ${ }^{+/-} / \mathrm{ARF}^{-/-}$mice. Moreover, no differences were observed between WT and ARF4 ${ }^{+1-}$, ARF5 ${ }^{-I-}$ Nav1.6 puncta in the white matter of their cerebella (Fig. 7E-G). These results suggest that class II ARFs mediate specifically the localization of Nav1.6 to the AIS of cerebellar PCs.

We next examined whether Nav1.6 localization is intact in the brain regions other than the cerebellum. The hippocampal CA1 region shows dense Nav1.6 immunoreactivity (Lorincz and Nusser, 2008). Nav1.6 immunoreactivity was severely decreased in ARF4 ${ }^{+/-} / \mathrm{ARF}^{-1-}$ pyramidal neurons of the hippocampal CA1 region as well (Fig. 8A,B). Specificity of anti-Nav1.6 antibody was confirmed by Western blotting using $\operatorname{Scn} 8 \mathrm{a}^{\mathrm{tg} / \mathrm{tg}}$ mice deprived of Nav1.6 expression (Burgess et al., 1995; Fig. 8C).

Ankyrin-G recruits other AIS components by providing a specific anchor for various AIS-specific proteins (Zhou et al., 1998; Jenkins and Bennett, 2001; Leterrier, 2018). We also examined cerebellar ankyrin-G clustering in the AIS by immunohistochemistry and found that ankyrin-G proteins were localized normally to the AISs of ARF4 ${ }^{+/-} /$ARF5 $^{-1-}$ PCs (Fig. 9A-C). In addition, the clustering of ankyrin-G in the AIS of hippocampal CA1 pyramidal neurons was similar between $\mathrm{WT}$ and $\mathrm{ARF} 4^{+/-}$/ ARF5 $^{-1-}$ neurons (Fig. 8A, B).
We next examined the localization of other Nav subtypes in the axons of PCs to explore the possibility of compensatory localization by other subtypes. Compared with WT, similar immunoreactivities were identified at the ARF4 ${ }^{+/-} / \mathrm{ARF}^{-/-}$AIS of PCs by using anti-pan-Navl antibody (Fig. 10A,B). There was no difference of Nav1.1 immunoreactivity between AIS of WT and $\mathrm{ARF}^{+/-} / \mathrm{ARF}^{-1-}$ PCs (Fig. 10C,D). On the other hand, Nav1.2 immunoreactivity was not localized at the AIS of either WT or ARF4 ${ }^{+/-} / \mathrm{ARF}^{-1-}$ PCs (Fig. 10E,F), which is consistent with previous reports (Schaller and Caldwell, 2003; Van Wart and Matthews, 2006; Kalume et al., 2007). Therefore, a compensatory distribution of other Navl subtypes to the ARF ${ }^{+-1}$, ARF5 ${ }^{-1-}$ AIS of PCs seems unlikely.

The Kv3 family of potassium channels is suggested to maintain high-frequency spiking in cerebellar PCs (Joho and Hurlock, 2009). In particular, Kv3.3, is suggested to be the dominant subtype expressed in the soma of adult cerebellar PCs (Southan and Robertson, 2000; McKay and Turner, 2005; Chang et al., 2007; Joho and Hurlock, 2009). Immunohistochemical analysis revealed a normal expression pattern of the $\mathrm{Kv} 3.3$ proteins in $\mathrm{ARF}^{+/-}{ }^{+\mathrm{ARF}^{-1-}}{ }^{-1}$ PCs (Fig. 10G,H). The whole-cell K ${ }^{+}$currents from PCs are extremely large, jeopardizing reliable measurement (Southan and Robertson, 2000). Therefore, we performed outside-out patch recordings from PC soma to exam- 

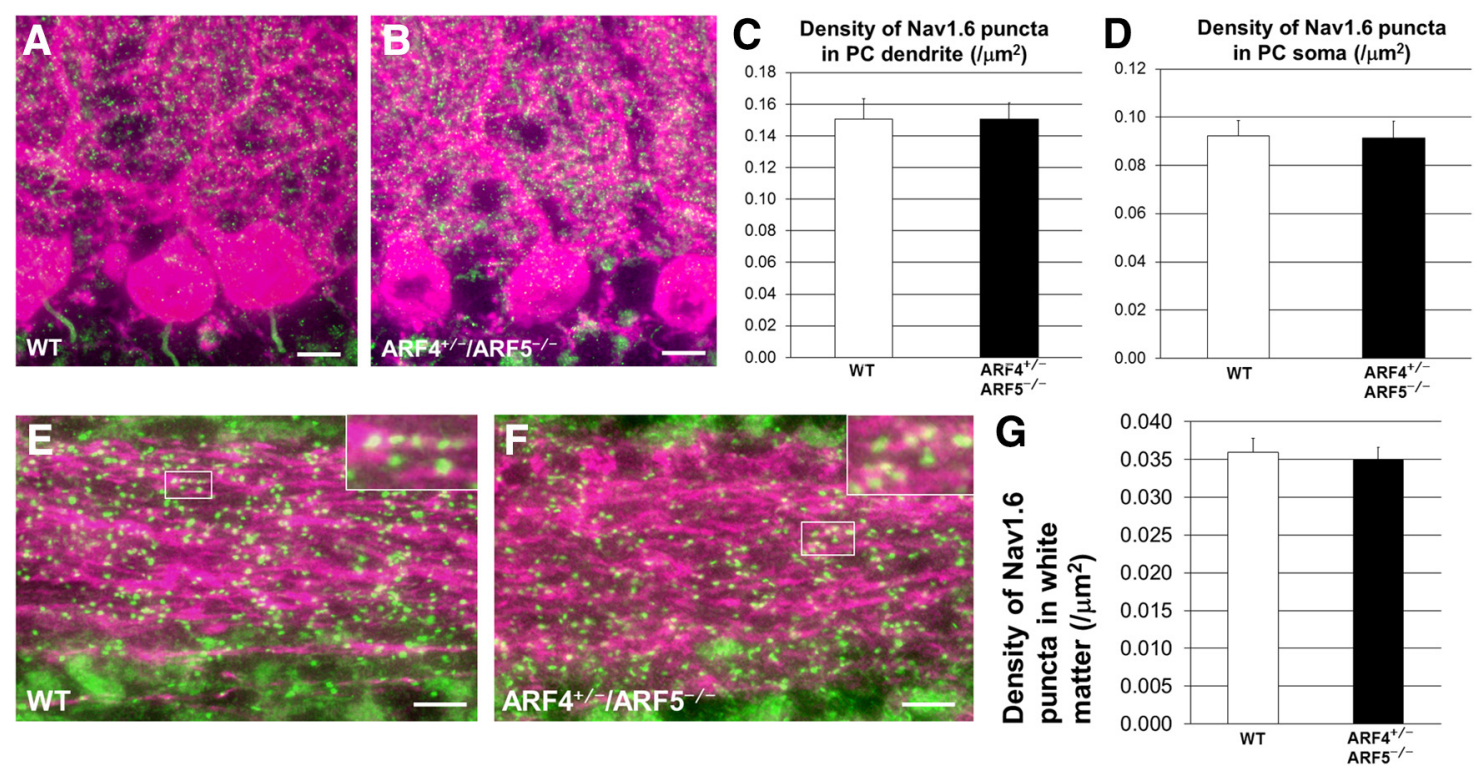

Figure 7. No difference in Nav1.6 puncta in soma, dendrites, or axons between WT and ARF4 ${ }^{+/-} /$ARF5 $^{-1-}$ PCS. $A, B$, Sagittal sections of postnatal week 8 (P8w) WT $(\boldsymbol{A})$ and ARF4 ${ }^{+/-}$/ ARF5 $^{-1-}(\boldsymbol{B})$ mouse cerebella were immunolabeled with an anti-Nav1.6 antibody (green) and an anti-calbindin (magenta) antibody. Scale bars, $20 \mu \mathrm{m}$. C, D, Densities of Nav1.6-positive puncta in primary and secondary dendrites $(\boldsymbol{C})$ and soma $(\boldsymbol{D})$ of WT (white; dendrite, $n=40$; soma, $n=48$ ) and ARF4 ${ }^{+/-} /$ARF5 $^{-1-} \mathrm{PCs}$ (black; dendrite, $n=40$; soma, $\left.n=61\right)$. $\boldsymbol{E}, \boldsymbol{F}$, Sagittal sections of P8W WT $(\boldsymbol{E})$ and ARF4 ${ }^{+/-} /$ARF5 $^{-1-}(\boldsymbol{F})$ cerebellar white matter were immunolabeled with an anti-Nav1.6 antibody (green) and an anti-calbindin (magenta) antibody. Enlarged images from rectangular white regions are shown in insets. Scale bars, $10 \mu \mathrm{m}$. G, Densities of Nav1.6-positive puncta in cerebellar white matter of WT (white; $n=34$ ) and ARF4 ${ }^{+/-} /$ARF5 $^{-/-}$PCs (black; $n=21$ ).
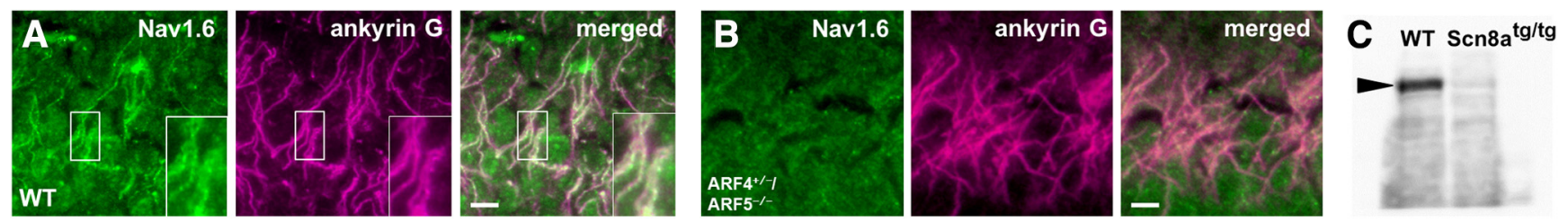

Figure 8. Nav1.6 localization to the AIS of hippocampal CA1 neurons in ARF4 ${ }^{+/-} / \mathrm{ARF}^{-1-}$ mice. $\boldsymbol{A}, \boldsymbol{B}$, Sagittal sections of postnatal week 8 WT $(\boldsymbol{A})$ and ARF4 ${ }^{+/-} /$ARF5 ${ }^{-1-}(\boldsymbol{B})$ mouse hippocampal CA1 regions were immunolabeled with an anti-Nav1.6 antibody (green) and an anti-ankyrin-G (magenta) antibody. Enlarged images from smaller rectangular white regions are shown in right lower insets. Scale bars, $10 \mu \mathrm{m}$. C, Immunoblot analysis of the P14 WT and Scn8a ${ }^{\mathrm{tg} / \mathrm{tg}}$ mice (Nav1.6-null mice). Protein lysates from the whole brain were immunoblotted with anti-Nav1.6 antibody. Arrowhead indicates the $229 \mathrm{kDa}$ position.
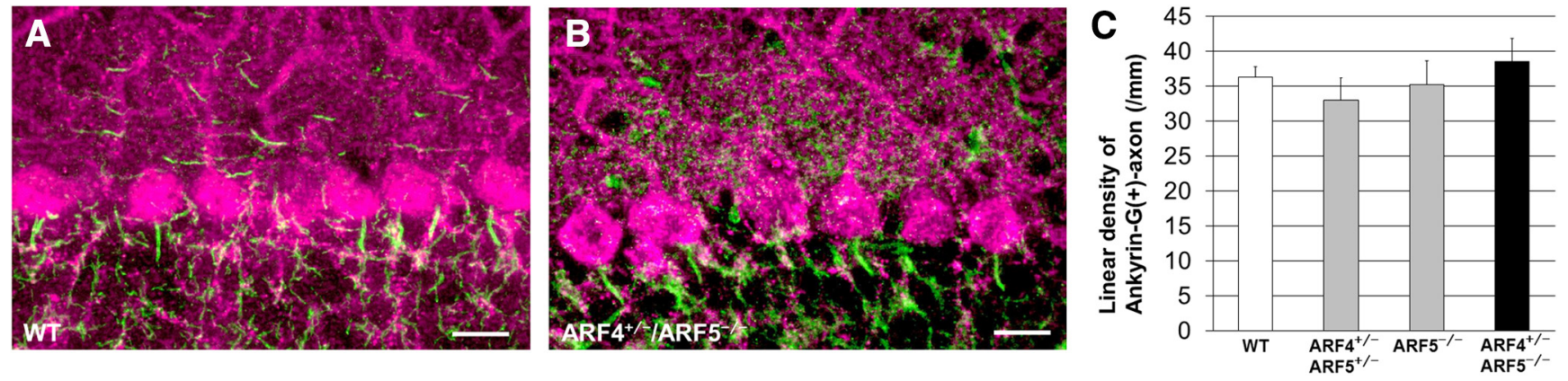

Figure 9. No difference in ankyrin-G immunoreactivity between WT and ARF4 ${ }^{+/-} / \mathrm{ARF}^{-/-} \mathrm{PCS} . \boldsymbol{A}, \boldsymbol{B}$, Sagittal sections of postnatal week 8 (P8W) WT (A) and ARF4 ${ }^{+/-} /$ARF5 $^{-/-}(\boldsymbol{B})$ mouse $^{-1}$ cerebella were immunolabeled with an anti-ankyrin-G antibody (green) and an anti-calbindin (magenta) antibody. Scale bars, $20 \mu \mathrm{m}$. C, The linear densities of ankyrin-G-positive axon of PCs for WT (white; $n=13)$, ARF4 $^{+/-} /$ARF5 $^{+/-}$(gray; $\left.n=16\right)$, ARF5 $^{-/-}$(gray; $\left.n=12\right)$, and ARF4 ${ }^{+/-} /$ARF $^{-/-}$mice (black; $\left.n=13\right)$ at P8W.

ine functional differences in somatic voltage-gated $\mathrm{K}^{+}$currents between WT and ARF4 ${ }^{+/-} / \mathrm{ARF}^{-1-}$ PCs. Depolarizing voltage pulses from $-85 \mathrm{mV}$ to voltage above $-35 \mathrm{mV}$ elicited outward currents (Fig. 10I), which were identified as $\mathrm{K}^{+}$currents because of their sensitivity to TEA and 4 -aminopyridine, voltage-gated $\mathrm{K}^{+}$channel blockers. No difference was observed in the peak amplitude of $\mathrm{K}^{+}$currents between WT and
$\mathrm{ARF}^{+/-} / \mathrm{ARF}^{-1-}$ PCs (Fig. 10J). These results imply neither anatomical nor functional alteration in voltagedependent $\mathrm{K}^{+}$channels between WT and ARF4 ${ }^{+/-} / \mathrm{ARF}^{-/-}$ PCs. Collectively, these immunohistochemical and electrophysiological results indicate that the impaired localization of Nav1.6 to the AIS may underlie the reduced PC excitability in $\mathrm{ARF}^{+/-} / \mathrm{ARF}^{-1-}$ mice. 

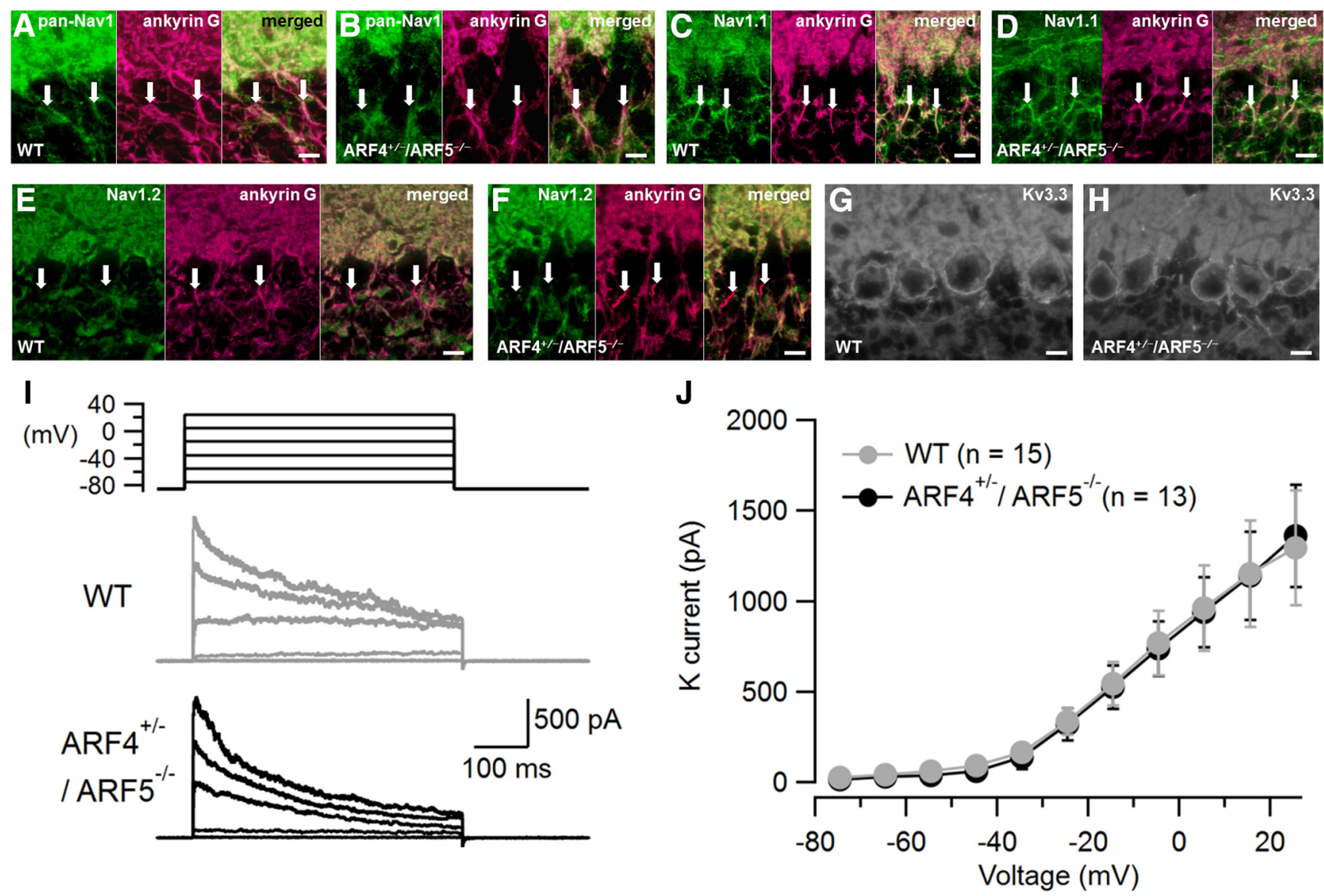

Figure 10. Immunoreactivities of pan-Nav1, Nav1.1, Nav1.2, and Kv3.3 in WT and ARF4 ${ }^{+/-} /$ARF5 $^{-/-}$PCS. A, B, Sagittal sections of postnatal week 8 (P8W) WT (A) and ARF4 ${ }^{+/-} /$ARF5 $^{-/-}$ (B) mouse cerebella were immunolabeled with an anti-pan-Nav1 antibody (green) and an anti-ankyrin-G (magenta) antibody. C, D, Sagittal sections of P8w WT (C) and ARF4 ${ }^{+/-} /$ARF5 $^{-1-}$ (D) mouse cerebella were immunolabeled with an anti-Nav1.1 antibody (green) and an anti-ankyrin-G (magenta) antibody. $\boldsymbol{E}, \boldsymbol{F}$, Sagittal sections of P8W WT (E) and ARF4 ${ }^{+/-} /$ARF5 $^{-/-}(\boldsymbol{F})$ mouse cerebella were immunolabeled with an anti-Nav1.2 antibody (green) and an anti-ankyrin-G (magenta) antibody. White arrows indicate ankyrin-G immunoreactivities in the AISs of PCs. $\mathbf{G}, \boldsymbol{H}$, Sagittal sections of P8W WT (G) and ARF4 ${ }^{+/-} /$ARF5 $^{-/-}(\boldsymbol{H})$ mouse cerebella were immunolabeled with an anti-Kv3.3 antibody. Scale bars, $10 \mathrm{~mm}$. $\boldsymbol{I}$, Representative traces of outside-out patch recordings in WT (gray) and ARF4 ${ }^{+1-} /$ ARF $^{-1-}$ (black) PCs. The outward currents evoked by 500 ms depolarizing voltage pulses were abolished by application of the voltage-dependent $\mathrm{K}^{+}$ current blockers TEA-CI $(10 \mathrm{~mm})$ and 4-aminopyridine $(2 \mathrm{mM}) . J$, Current-voltage relations of voltage-dependent $\mathrm{K}^{+}$currents with protocols shown in $/$. The $\mathrm{K}^{+}$currents were similar between WT (gray) and ARF4 ${ }^{+/-} /$ARF5 $^{-I-}$ (black) PCs [Repeated-measures two-way ANOVA, genotype effect $\left(F_{(1,26)}=0.012 ; P=0.915\right)$, interaction (genotype $\times$ voltage; $\left.\left.F_{(10,260)}=0.039 ; p>0.999\right)\right]$.
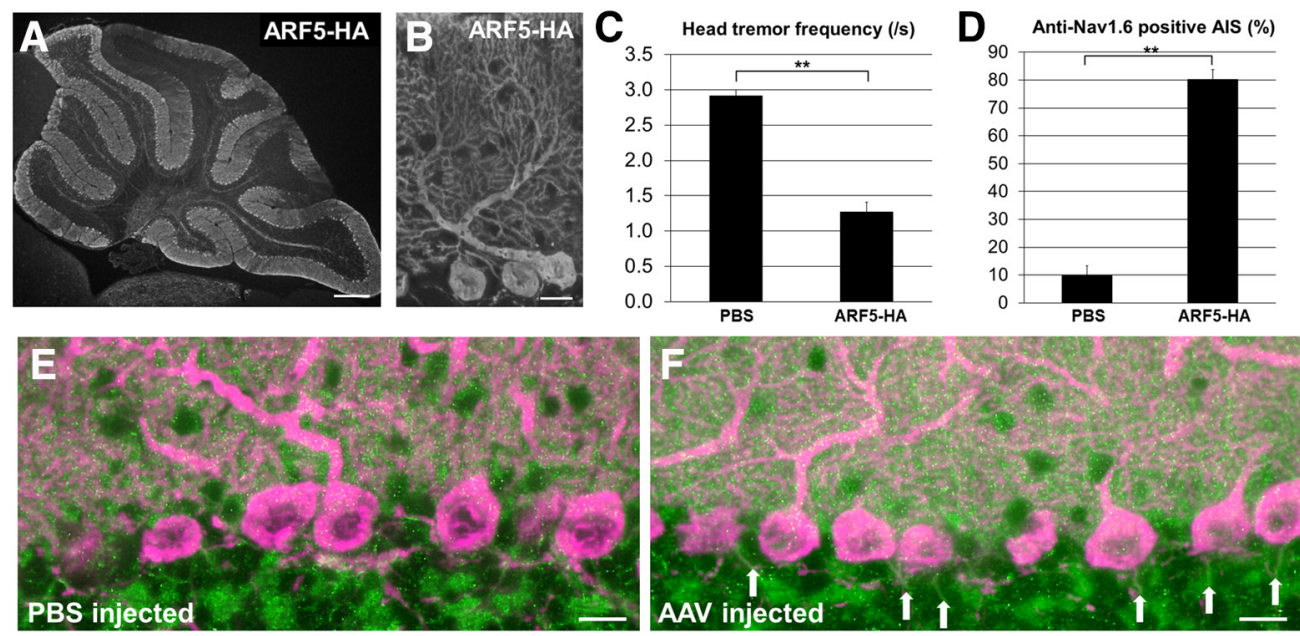

Figure 11. Rescue of ARF4 ${ }^{+/-} /$ARF $^{-1-}$ phenotypes by exogenous ARF5 expression in the cerebellar PCs. $A, B$, Sagittal section of a postnatal week 8 (P8w) mouse cerebellum injected with AAV9 vectors expressing ARF5-HA at P14 and immunolabeled with an anti-HA antibody. Scale bars: $A, 300 \mu \mathrm{m} ; \boldsymbol{B}, 20 \mu \mathrm{m}$. C, Head-tremor frequency of P8w mouse during 3 min of movement was counted from video recordings. ARF4 ${ }^{+/-} /$ARF5 $^{-1-}$ mice were injected PBS $(n=12)$ or AAV9 vectors expressing ARF5-HA $(n=12)$ at P14. ${ }^{* *} p<0.001$, Student's $t$ test. $\boldsymbol{D}$, The proportion of Nav1.6-positive AISs to ankyrin-G-positive AISs in ARF4 ${ }^{+/-} /$ARF5 $^{-1-}$ mice injected with PBS $(n=24)$ and AAV9 vectors expressing ARF5-HA $(n=33)$ at P8w. ${ }^{* *} p<0.001$, Student's $t$ test. $\boldsymbol{E}$, $\boldsymbol{F}$, Sagittal sections of P8W ARF4 ${ }^{+-}$/ARF5 ${ }^{-1-}$ mouse cerebella injected with PBS $(\boldsymbol{E})$ or AAV9 vectors expressing ARF5-HA $(\boldsymbol{F})$ immunolabeled with anti-Nav1.6 (green) and anti-calbindin (magenta) antibodies. White arrows indicate Nav1.6 immunoreactivities in the AIS of PCs. Scale bars, $20 \mu \mathrm{m}$. 
Decreased Nav1.6 expression and the consequent tremors are alleviated by PC-specific expression of ARF5

To examine whether the morphological and behavioral defects of ARF4 ${ }^{+/-} / \mathrm{ARF}^{-/-}$mice were actually caused by the loss of class II ARF proteins in cerebellar PCs, we performed a rescue experiment in which ARF5 proteins were expressed specifically in PCs of ARF4 ${ }^{+/-} / \mathrm{ARF}^{-/-}$mice using AAV9 expression vectors. AAV9 expressing ARF5 tagged with HA under the control of PC-specific L7 promoter, was directly administered into the $\mathrm{ARF}^{+/-} / \mathrm{ARF}^{-/-}$cerebellum at P14 as described previously (Sawada et al., 2010). The expression of the transgene in the cerebellum was examined 6 weeks after the injection. Figure 11, $A$ and $B$, shows representative sagittal sections of the cerebellar vermis from ARF $4^{+/-} / \mathrm{ARF}^{-1-}$ mice injected with the AAV vectors. ARF5 was diffusely expressed in all lobules of the ARF4 ${ }^{+/-}$/ ARF5 $^{-1-}$ mouse cerebellar vermis (Fig. 11A) and its expression was limited to PCs (Fig. 11B). The frequency of head shaking of the AAV-injected mice was significantly decreased compared with that of the PBS-injected mice (Fig. 11C). Concomitantly, the proportion of Nav1.6 expression in the AIS of PCs was increased in the ARF5-restored ARF4 ${ }^{+/-} / \mathrm{ARF}^{-/-}$mice compared with that in the PBS-injected mice (control; Fig. 11D-F). Thus, the abnormal behavioral and immunohistochemical phenotypes (i.e., tremor and Nav1.6 mislocalization) were partly rescued by PC-specific class II ARF protein expression. Therefore, we conclude that class II ARF deficiency in cerebellar PCs can contribute to ET directly through impaired localization of Nav1.6 to the AIS.

\section{Discussion}

In the present study, we generated class II ARF-deficient mice (ARF4 $^{+/-} / \mathrm{ARF}^{-/-}$; Fig. 1) and demonstrated that class II ARF deficiency caused severe tremors (Movie 1; Fig. 2). In our results, the ECoG of ARF4 $4^{+/-} / \mathrm{ARF} 5^{-/-}$mice was dramatically changed during periods of movement while there was no difference between the mutant and WT mice during resting periods (Fig. 3). Pharmacological treatment, which alleviate ET in patients, similarly reduced the frequency of the movement-associated tremors in the ARF4 ${ }^{+/-} / \mathrm{ARF}^{-/-}$mice (Fig. 2). Electrophysiological analyses revealed abnormal AP firing and reduced $\mathrm{Na}^{+}$current in cerebellar PCs (Figs. 4-6). Furthermore, we found that localization of Nav1.6 proteins to the AIS in PCs was selectively impaired in ARF4 ${ }^{+/-} / \mathrm{ARF}^{-1-}$ mice (Fig. 6). The failure in localization of Nav1.6 was not because of any malformation of the AIS because localization of cytoskeletal ankyrin-G scaffold protein, the defining molecular component of the AIS (Zhang and Rasband, 2016), was normally localized as observed in the WT mice (Fig. 9). These results clearly demonstrate that class II ARFs function in localizing Nav1.6 to the AIS. In addition, PCspecific transgene expression of class II ARF (ARF5) in ARF4 ${ }^{+/-}$/ $\mathrm{ARF}^{-/-}$mice restored the proper distribution of Nav1.6 proteins in the AIS, and reduced movement-associated tremors (Fig. 11). These data support a significant association between the class II ARF expressed in PCs and the tremors. Our studies with this animal model suggest that the ET pathology involves reduced intrinsic excitability of cerebellar PCs because of a disruption of class II ARF-dependent localizing of Nav1.6 to the AIS. Therefore, we propose a novel causative mechanism of ET in which the loss of AIS ion channels induces tremor.

\section{Function of class II ARFs}

Little is known about the role of class II ARFs in membrane trafficking. It has been documented that class II ARFs are involved in Dengue virus secretion (Kudelko et al., 2012) and hep- atitis C virus replication (Farhat et al., 2016), although the specific mechanisms remain unclear. In this study, we identified for the first time a functional role of class II ARF in regulating Nav1.6 protein localization to the AIS (Fig. 6). The AIS has two important physiological functions. One is to initiate APs, and another is to form an axonal barrier (Zhang and Rasband, 2016). In our analysis, class II ARFs are not involved in the formation of the AIS (Fig. 9), suggesting that ARF4 ${ }^{+/-} / \mathrm{ARF}^{-/-}$PCs have normal axonal barrier functions to prevent nonspecific transport from the soma to the axon. Moreover, our results suggest that the class II ARFs are irrelevant to localizing Nav1.6 to the somatodendritic compartment and to the nodes of Ranvier (Fig. 7). Notably, our data clearly indicate that class II ARFs specifically regulate Nav1.6 localization to the AIS. Therefore, class II ARFs may play a role as "ion channel organizers" at the AIS.

Ankyrin-G binds directly to an interaction motif within the II-III intracellular loop of the Nav1.6 channel, which results in a high localization of Nav1.6 channels to the AIS (Garrido et al., 2003; Lemaillet et al., 2003; Gasser et al., 2012; Akin et al., 2015). Indeed, genetic ablation of ankyrin-G blocked AIS Na ${ }^{+}$channel clustering (Zhou et al., 1998; Ho et al., 2014). In ARF4 ${ }^{+/-}$/ $\mathrm{ARF}^{-1-}$ mouse PCs, however, localization of ankyrin-G to the AIS was similar to that observed in WT (Fig. 9). Therefore, $\mathrm{ARF} 4^{+/-} / \mathrm{ARF}^{-1-}$ mouse PCs may display a failure in trafficking Nav1.6 proteins to the AIS via an ankyrin-G-independent mechanism. However, it is also possible that the decreased localization of Nav1.6 to the AIS depends on the enhanced Nav1.6 endocytosis from the AIS, rather than a reduced forward trafficking to the AIS (Solé et al., 2019). The trafficking of Nav1.6 proteins to the AIS needs to be examined directly in real-time imaging to determine whether the maintenance of Nav1.6 proteins in the AIS is affected.

\section{ET and cerebellar PCs}

ET is the most frequent movement disorder, with a prevalence of $\sim 4 \%$ among adults aged 40 years and older (Louis et al., 1995). In contrast to the resting tremor that is observed in Parkinson disease, ET is characterized by postural and kinetic components (Pahwa and Lyons, 2003). Growing clinical and neuro-imaging evidence has implicated cerebellar dysfunction in the pathogenesis of ET, and emerging postmortem studies have identified structural changes in the cerebellum (Kralic et al., 2005; Louis et al., 2007; Benito-León et al., 2009; Elble and Deuschl, 2011; Kuo et al., 2011). In this report, based on the AAV-mediated PCspecific gene-rescue experiment, we clearly demonstrate the contribution of cerebellar PCs to the tremor pathology in $\mathrm{ARF}^{+/-}$, $\mathrm{ARF}^{-1-}$ mice (Fig. 11). However, the PC-specific genetic rescue did not fully rectify the tremor phenotype in ARF4 ${ }^{+/-} / \mathrm{ARF} 5^{-1-}$ mice. This is likely attributable to insufficient class II ARF proteins expressed in the whole cerebellum. Alternatively, a possible abnormality in other regions, including the motor pathway, in addition to cerebellar PCs may be involved in the ET pathology, as proposed by Kralic et al. (2005). The abnormal ECoG observed in ARF4 ${ }^{+/-} / \mathrm{ARF}^{-1-}$ mice (Fig. 3) may reflect the aberrant AP firing of neurons in the cerebral cortex to which we did not deliver the rescue vector virus in the present study.

In ARF $4^{+/-} / \mathrm{ARF}^{-1-} \mathrm{PCs}$, reduced AP firing was observed in response to larger current inputs, whereas smaller current inputs induced normal AP firing (Fig. 4). Climbing fiber (CF) synaptic input to PCs can be a physiological strong excitatory drive, which induces a burst of spikes (i.e., complex spike; Mathy et al., 2009). In ARF4 ${ }^{+/-} / \mathrm{ARF}^{-1-}$ mice, CF-evoked burst spikes can 
be reduced in PCs, leading to abnormality in PC synaptic plasticity (long-term depression), integration, and output to DCN neurons (Khaliq and Raman, 2005; Monsivais et al., 2005; Mathy et al., 2009). On the other hand, the phenotype of input strengthdependent AP reduction may be related to the behavioral phenotype in $\mathrm{ARF} 4^{+/-} / \mathrm{ARF}^{-/-}$mice, where tremor-like head shaking occurs only during locomotion, but not at rest. Locomotion increases cerebellar granule cell activity (i.e., excitatory inputs to PCs) and consequently, some PCs increase their simple spike firing rates during movement in vivo (Jelitai et al., 2016). Therefore, PCs are likely to receive fewer spontaneous synaptic current inputs at rest while receiving many more excitatory synaptic current inputs during locomotion. In that context, it is possible that tremors occur in $\mathrm{ARF} 4^{+/-} / \mathrm{ARF} 5^{-/-}$mice during movement only because their PCs may be unable to maintain AP firing properly in response to movement-driven "increased" synaptic inputs. On the other hand, PCs in $\mathrm{ARF} 4^{+/-} / \mathrm{ARF} 5^{-/-}$mice are spontaneously less active (Fig. 4). Both the lower excitability at baseline and the lower evoked firing activity in PCs in vivo may contribute to the abnormal behavioral phenotype of $\mathrm{ARF}^{+/-}$/ ARF5 $^{-1-}$ mice (Buttermore et al., 2012; Ransdell et al., 2017; Valkova et al., 2017).

Nav1.1 and Nav1.6 are predominant pore-forming $\alpha$ subunits in WT PCs (Schaller and Caldwell, 2003), and the AIS is a critical site for AP initiation in PCs (Foust et al., 2010; Palmer et al., 2010). Our study revealed that Nav1.6-mediated $\mathrm{Na}^{+}$currents (both their transient and resurgent components) are reduced in $\mathrm{ARF}^{+/-} / \mathrm{ARF}^{-/-}$PCs (Figs. 5, 6). Although the precise mechanism of the resurgent $\mathrm{Na}^{+}$current remains undetermined, the $\mathrm{Na}^{+}$channel $\beta 4$ subunit is critically important for generating the resurgent $\mathrm{Na}^{+}$current (Grieco et al., 2005; Ransdell et al., 2017). In this context, class II ARF dysfunction might also affect the $\beta 4$ subunit expression or function and in turn might result in reduction of the resurgent current in $\mathrm{ARF} 4^{+/-} / \mathrm{ARF} 5^{-1-} \mathrm{PCs}$.

The present study revealed that ARF $4^{+/-} / \mathrm{ARF} 5^{-1-} \mathrm{PCs}$ are unable to sustain AP firing and show a reduced AP amplitude during their burst AP firing (Fig. 4). These phenomena can be ascribed solely to the decrease in the resurgent $\mathrm{Na}^{+}$current in ARF4 ${ }^{+/-} / \mathrm{ARF}^{-1-}$ PCs (Fig. 6) and neither to the change in voltage-gated $\mathrm{K}^{+}$current (Fig. 10) nor to the alteration in $\mathrm{Na}^{+}$ channel inactivation (Fig. 5). This is consistent with several previous studies suggesting that the resurgent current plays a critical role in repetitive firing (Lewis and Raman, 2014; Ransdell and Nerbonne, 2018). Our findings also resemble the recent report by Ransdell et al. (2017) showing that the decrease in resurgent $\mathrm{Na}^{+}$ currents in $\beta 4$-deficient mice contributes to reduction in spike firing in PCs regardless of unchanged activation or inactivation properties of the $\mathrm{Na}^{+}$channels. However, we cannot rule out the possibility that other $\mathrm{K}^{+}$channels, such as $\mathrm{Ca}^{2+}$-activated $\mathrm{K}^{+}$ channels or other ion channels, which could not be addressed in the present study, may also contribute to the reduction in spiking in ARF4 ${ }^{+/-} / \mathrm{ARF}^{-1-}$ PCs.

It should be noted that the pathologic tremor of our class II ARF-deficient mice showed a remarkable pharmacological similarity with that of human patients with ET. Thus, the dysfunction of class II ARFs and the consequent impaired distribution of an ion channel (i.e., loss of Nav1.6) at the AIS may be underlying causes of human ET. We propose ARF4 $4^{+/-} / \mathrm{AFR} 5^{-/-}$mice as a suitable animal model to elucidate the mechanisms of ET in humans, which may contribute to the development of future therapeutic interventions.

\section{References}

Akin EJ, Solé L, Dib-Hajj SD, Waxman SG, Tamkun MM (2015) Preferential targeting of Nav1.6 voltage-gated $\mathrm{Na}^{+}$Channels to the axon initial segment during development. PloS one 10:e0124397.

Bekkers JM, Häusser M (2007) Targeted dendrotomy reveals active and passive contributions of the dendritic tree to synaptic integration and neuronal output. Proc Natl Acad Sci U S A 104:11447-11452.

Benito-León J, Alvarez-Linera J, Hernández-Tamames JA, Alonso-Navarro H, Jiménez-Jiménez FJ, Louis ED (2009) Brain structural changes in essential tremor: voxel-based morphometry at 3-tesla. J Neurol Sci 287:138-142.

Bosch MK, Carrasquillo Y, Ransdell JL, Kanakamedala A, Ornitz DM, Nerbonne JM (2015) Intracellular FGF14 (iFGF14) is required for spontaneous and evoked firing in cerebellar Purkinje neurons and for motor coordination and balance. J Neurosci 35:6752-6769.

Burgess DL, Kohrman DC, Galt J, Plummer NW, Jones JM, Spear B, Meisler MH (1995) Mutation of a new sodium channel gene, Scn8a, in the mouse mutant "motor endplate disease". Nat Genet 10:461-465.

Buttermore ED, Piochon C, Wallace ML, Philpot BD, Hansel C, Bhat MA (2012) Pinceau organization in the cerebellum requires distinct functions of neurofascin in Purkinje and basket neurons during postnatal development. J Neurosci 32:4724-4742.

Cen ZD, Xie F, Xiao JF, Luo W (2016) Rational search for genes in familial cortical myoclonic tremor with epilepsy, clues from recent advances. Seizure 34:83-89.

Chang SY, Zagha E, Kwon ES, Ozaita A, Bobik M, Martone ME, Ellisman MH, Heintz N, Rudy B (2007) Distribution of Kv3.3 potassium channel subunits in distinct neuronal populations of mouse brain. J Comp Neurol 502:953-972.

Cockcroft S, Thomas GM, Fensome A, Geny B, Cunningham E, Gout I, Hiles I, Totty NF, Truong O, Hsuan JJ (1994) Phospholipase D: a downstream effector of ARF in granulocytes. Science 263:523-526.

Donaldson JG, Jackson CL (2011) ARF family G proteins and their regulators: roles in membrane transport, development and disease. Nat Rev Mol Cell Biol 12:362-375.

Dursun SM, Handley SL (1993) The effects of alpha 2-adrenoceptor antagonists on the inhibition of 1-(2,5-dimethoxy-4-iodophenyl)-2aminopropane (DOI)-induced head shakes by 5 -HT1A receptor agonists in the mouse. Br J Pharmacol 109:1046-1052.

Elble R, Deuschl G (2011) Milestones in tremor research. Mov Disord 26: 1096-1105.

Farhat R, Séron K, Ferlin J, Fénéant L, Belouzard S, Goueslain L, Jackson CL, Dubuisson J, Rouillé Y (2016) Identification of class II ADPribosylation factors as cellular factors required for hepatitis $\mathrm{C}$ virus replication. Cell Microbiol 18:1121-1133.

Foust A, Popovic M, Zecevic D, McCormick DA (2010) Action potentials initiate in the axon initial segment and propagate through axon collaterals reliably in cerebellar Purkinje neurons. J Neurosci 30:6891-6902.

Garrido JJ, Giraud P, Carlier E, Fernandes F, Moussif A, Fache MP, Debanne D, Dargent B (2003) A targeting motif involved in sodium channel clustering at the axonal initial segment. Science 300:2091-2094.

Gasser A, Ho TS, Cheng X, Chang KJ, Waxman SG, Rasband MN, Dib-Hajj SD (2012) An ankyrinG-binding motif is necessary and sufficient for targeting Nav1.6 sodium channels to axon initial segments and nodes of Ranvier. J Neurosci 32:7232-7243.

Grieco TM, Malhotra JD, Chen C, Isom LL, Raman IM (2005) Openchannel block by the cytoplasmic tail of sodium channel $\beta 4$ as a mechanism for resurgent sodium current. Neuron 45:233-244.

Ho TS, Zollinger DR, Chang KJ, Xu M, Cooper EC, Stankewich MC, Bennett V, Rasband MN (2014) A hierarchy of ankyrin-spectrin complexes clusters sodium channels at nodes of Ranvier. Nat Neurosci 17:1664-1672.

Hwang DY, Fleming SM, Ardayfio P, Moran-Gates T, Kim H, Tarazi FI, Chesselet MF, Kim KS (2005) 3,4-dihydroxyphenylalanine reverses the motor deficits in Pitx3-deficient aphakia mice: behavioral characterization of a novel genetic model of Parkinson's disease. J Neurosci 25:21322137.

Jain S, Yoon SY, Zhu L, Brodbeck J, Dai J, Walker D, Huang Y (2012) Arf4 determines dentate gyrus-mediated pattern separation by regulating dendritic spine development. PloS one 7:e46340.

Jelitai M, Puggioni P, Ishikawa T, Rinaldi A, Duguid I (2016) Dendritic excitation-inhibition balance shapes cerebellar output during motor behaviour. Nat Commun 7:13722. 
Jenkins SM, Bennett V (2001) Ankyrin-G coordinates assembly of the spectrin-based membrane skeleton, voltage-gated sodium channels, and L1 CAMs at Purkinje neuron initial segments. J Cell Biol 155:739-746.

Joho RH, Hurlock EC (2009) The role of Kv3-type potassium channels in cerebellar physiology and behavior. Cerebellum 8:323-333.

Kalume F, Yu FH, Westenbroek RE, Scheuer T, Catterall WA (2007) Reduced sodium current in Purkinje neurons from Nav1.1 mutant mice: implications for ataxia in severe myoclonic epilepsy in infancy. J Neurosci 27:11065-11074.

Khaliq ZM, Raman IM (2005) Axonal propagation of simple and complex spikes in cerebellar Purkinje neurons. J Neurosci 25:454-463.

Kiyonari H, Kaneko M, Abe S, Aizawa S (2010) Three inhibitors of FGF receptor, ERK, and GSK3 establishes germline-competent embryonic stem cells of C57BL/6N mouse strain with high efficiency and stability. Genesis 48:317-327.

Kole MH, Stuart GJ (2012) Signal processing in the axon initial segment. Neuron 73:235-247.

Kralic JE, Criswell HE, Osterman JL, O'Buckley TK, Wilkie ME, Matthews DB, Hamre K, Breese GR, Homanics GE, Morrow AL (2005) Genetic essential tremor in gamma-aminobutyric acidA receptor alphal subunit knockout mice. J Clin Invest 115:774-779.

Kudelko M, Brault JB, Kwok K, Li MY, Pardigon N, Peiris JS, Bruzzone R, Desprès P, Nal B, Wang PG (2012) Class II ADP-ribosylation factors are required for efficient secretion of dengue viruses. J Biol Chem 287:767-777.

Kuo SH, Erickson-Davis C, Gillman A, Faust PL, Vonsattel JP, Louis ED (2011) Increased number of heterotopic Purkinje cells in essential tremor. J Neurol Neurosurg Psychiatry 82:1038-1040.

Lemaillet G, Walker B, Lambert S (2003) Identification of a conserved ankyrin-binding motif in the family of sodium channel alpha subunits. J Biol Chem 278:27333-27339.

Leterrier C (2018) The axon initial segment: an updated viewpoint. J Neurosci 38:2135-2145.

Levin SI, Khaliq ZM, Aman TK, Grieco TM, Kearney JA, Raman IM, Meisler MH (2006) Impaired motor function in mice with cell-specific knockout of sodium channel Scn8a (Nav1.6) in cerebellar Purkinje neurons and granule cells. J Neurophysiol 96:785-793.

Lewis AH, Raman IM (2014) Resurgent current of voltage-gated $\mathrm{Na}^{+}$channels. J Physiol 592:4825-4838.

Lorincz A, Nusser Z (2008) Cell-type-dependent molecular composition of the axon initial segment. J Neurosci 28:14329-14340.

Louis ED, Marder K, Cote L, Pullman S, Ford B, Wilder D, Tang MX, Lantigua R, Gurland B, Mayeux R (1995) Differences in the prevalence of essential tremor among elderly African Americans, whites, and Hispanics in northern Manhattan, NY. Arch Neurol 52:1201-1205.

Louis ED, Faust PL, Vonsattel JP, Honig LS, Rajput A, Robinson CA, Rajput A, Pahwa R, Lyons KE, Ross GW, Borden S, Moskowitz CB, Lawton A, Hernandez N (2007) Neuropathological changes in essential tremor: 33 cases compared with 21 controls. Brain 130:3297-3307.

Mathy A, Ho SS, Davie JT, Duguid IC, Clark BA, Häusser M (2009) Encoding of oscillations by axonal bursts in inferior olive neurons. Neuron 62:388-399.

McKay BE, Turner RW (2005) Physiological and morphological development of the rat cerebellar Purkinje cell. J Physiol 567:829-850.

Meisler MH, Kearney JA (2005) Sodium channel mutations in epilepsy and other neurological disorders. J Clin Invest 115:2010-2017.

Milescu LS, Bean BP, Smith JC (2010) Isolation of somatic $\mathrm{Na}^{+}$currents by selective inactivation of axonal channels with a voltage prepulse. J Neurosci 30:7740-7748.

Mitsumura K, Hosoi N, Furuya N, Hirai H (2011) Disruption of metabotropic glutamate receptor signalling is a major defect at cerebellar parallel fibre-Purkinje cell synapses in staggerer mutant mice. J Physiol 589: 3191-3209.

Miyake K, Miyake N, Yamazaki Y, Shimada T, Hirai Y (2012) Serotypeindependent method of recombinant adeno-associated virus (AAV) vector production and purification. J Nippon Med Sch 79:394-402.

Mizuno-Yamasaki E, Rivera-Molina F, Novick P (2012) GTPase networks in membrane traffic. Annu Rev Biochem 81:637-659.

Monsivais P, Clark BA, Roth A, Häusser M (2005) Determinants of action potential propagation in cerebellar Purkinje cell axons. J Neurosci 25:464-472.

Nicholls JG, Martin RG, Wallace BG, Fuchs PA (2001) From neuron to brain, Ed 4. Sunderland, MA: Sinauer.

Pahwa R, Lyons KE (2003) Essential tremor: differential diagnosis and current therapy. Am J Med 115:134-142.

Palmer LM, Clark BA, Gründemann J, Roth A, Stuart GJ, Häusser M (2010) Initiation of simple and complex spikes in cerebellar Purkinje cells. J Physiol 588:1709-1717.

Raman IM, Sprunger LK, Meisler MH, Bean BP (1997) Altered subthreshold sodium currents and disrupted firing patterns in Purkinje neurons of Scn8a mutant mice. Neuron 19:881-891.

Ransdell JL, Nerbonne JM (2018) Voltage-gated sodium currents in cerebellar Purkinje neurons: functional and molecular diversity. Cell Mol Life Sci 75:3495-3505.

Ransdell JL, Dranoff E, Lau B, Lo WL, Donermeyer DL, Allen PM, Nerbonne JM (2017) Loss of Nav $\beta 4$-mediated regulation of sodium currents in adult Purkinje neurons disrupts firing and impairs motor coordination and balance. Cell Rep 19:532-544.

Rothman JS, Silver RA (2018) NeuroMatic: an integrated open-source software toolkit for acquisition, analysis and simulation of electrophysiological data. Front Neuroinform 12:14.

Sadakata T, Shinoda Y, Sekine Y, Saruta C, Itakura M, Takahashi M, Furuichi $\mathrm{T}$ (2010) Interaction of calcium-dependent activator protein for secretion 1 (CAPS1) with the class II ADP-ribosylation factor small GTPases is required for dense-core vesicle trafficking in the trans-Golgi network. J Biol Chem 285:38710-38719.

Sakai K, Miyazaki J (1997) A transgenic mouse line that retains cre recombinase activity in mature oocytes irrespective of the cre transgene transmission. Biochem Biophys Res Commun 237:318-324.

Sawada Y, Kajiwara G, Iizuka A, Takayama K, Shuvaev AN, Koyama C, Hirai H (2010) High transgene expression by lentiviral vectors causes maldevelopment of Purkinje cells in vivo. Cerebellum 9:291-302.

Schaller KL, Caldwell JH (2003) Expression and distribution of voltagegated sodium channels in the cerebellum. Cerebellum 2:2-9.

Schweitzer JK, Sedgwick AE, D'Souza-Schorey C (2011) ARF6-mediated endocytic recycling impacts cell movement, cell division and lipid homeostasis. Semin Cell Dev Biol 22:39-47.

Shibasaki K, Sugio S, Takao K, Yamanaka A, Miyakawa T, Tominaga M, Ishizaki Y (2015) TRPV4 activation at the physiological temperature is a critical determinant of neuronal excitability and behavior. Pflugers Arch 467:2495-2507.

Solé L, Wagnon JL, Akin EJ, Meisler MH, Tamkun MM (2019) The MAP1B binding domain of Nav1.6 is required for stable expression at the axon initial segment. J Neurosci 39:4238-4251.

Southan AP, Robertson B (2000) Electrophysiological characterization of voltage-gated $\mathrm{K}^{+}$currents in cerebellar basket and Purkinje cells: Kv1 and $\mathrm{Kv} 3$ channel subfamilies are present in basket cell nerve terminals. J Neurosci 20:114-122.

Valkova C, Liebmann L, Krämer A, Hübner CA, Kaether C (2017) The sorting receptor Rer 1 controls purkinje cell function via voltage gated sodium channels. Sci Rep 7:41248.

Van Wart A, Matthews G (2006) Impaired firing and cell-specific compensation in neurons lacking nav1.6 sodium channels. J Neurosci 26: 7172-7180.

Volpicelli-Daley LA, Li Y, Zhang CJ, Kahn RA (2005) Isoform-selective effects of the depletion of ADP-ribosylation factors $1-5$ on membrane traffic. Mol Biol Cell 16:4495-4508.

Zhang C, Rasband MN (2016) Cytoskeletal control of axon domain assembly and function. Curr Opin Neurobiol 39:116-121.

Zhao S, Ting JT, Atallah HE, Qiu L, Tan J, Gloss B, Augustine GJ, Deisseroth K, Luo M, Graybiel AM, Feng G (2011) Cell type-specific channelrhodopsin-2 transgenic mice for optogenetic dissection of neural circuitry function. Nat methods 8:745-752.

Zhou D, Lambert S, Malen PL, Carpenter S, Boland LM, Bennett V (1998) AnkyrinG is required for clustering of voltage-gated Na channels at axon initial segments and for normal action potential firing. J Cell Biol 143: 1295-1304. 